OPEN ACCESS

Edited by:

Lena Alexopoulou,

INSERM U1104 Centre

d'immunologie de Marseille-Luminy

(CIML), France

Reviewed by:

Nilesh C. Sharma,

Western Kentucky University,

United States

Kenneth Michael Pollard,

The Scripps Research Institute,

United States

${ }^{*}$ Correspondence:

Xin M. LuO

xinluo@vt.edu

Specialty section: This article was submitted to Autoimmune and

Autoinflammatory Disorders,

a section of the journal

Frontiers in Immunology

Received: 29 July 2021 Accepted: 13 December 2021

Published: 05 January 2022

Citation:

Abdelhamid $L$ and $L$ Lo XM (2022) Diet and Hygiene in

Modulating Autoimmunity

During the Pandemic Era.

Front. Immunol. 12:749774. doi: 10.3389/fimmu.2021.749774

\section{Diet and Hygiene in Modulating Autoimmunity During the Pandemic Era}

\author{
Leila Abdelhamid ${ }^{1,2}$ and Xin M. Luo ${ }^{1 *}$ \\ 1 Department of Biomedical Sciences and Pathobiology, College of Veterinary Medicine, Virginia Tech, Blacksburg, \\ VA, United States, ${ }^{2}$ Department of Microbiology, College of Veterinary Medicine, Alexandria University, Alexandria, Egypt
}

The immune system is an efficiently toned machinery that discriminates between friends and foes for achieving both host defense and homeostasis. Deviation of immune recognition from foreign to self and/or long-lasting inflammatory responses results in the breakdown of tolerance. Meanwhile, educating the immune system and developing immunological memory are crucial for mounting defensive immune responses while protecting against autoimmunity. Still to elucidate is how diverse environmental factors could shape autoimmunity. The emergence of a world pandemic such as SARS-CoV-2 (COVID-19) not only threatens the more vulnerable individuals including those with autoimmune conditions but also promotes an unprecedented shift in people's dietary approaches while urging for extraordinary hygiene measures that likely contribute to the development or exacerbation of autoimmunity. Thus, there is an urgent need to understand how environmental factors modulate systemic autoimmunity to better mitigate the incidence and or severity of COVID-19 among the more vulnerable populations. Here, we discuss the effects of diet (macronutrients and micronutrients) and hygiene (the use of disinfectants) on autoimmunity with a focus on systemic lupus erythematosus.

Keywords: diet, hygiene, immunomodulation, immune homeostasis, autoimmunity, COVID-19

\section{INTRODUCTION}

The immune system is highly toned and efficiently dedicated to maintaining health by protecting against a tremendous array of invaders (1). Our body faces continuous challenges that might be represented in biological threats (such as, but not limited to, microbial pathogens) and physical threats (such as radiation and chemicals). The immune system is equipped with both innate and adaptive arms to fight against these threats (1). The ultimate goal of our immune system is to induce an effective and balanced inflammatory response that enables the efficient elimination of possible threats without causing excessive collateral tissue damage (2). Therefore, an optimal immune response includes recognition, mounting an overarching reaction, then returning to normal homeostasis without skewing to either immunodeficiency or autoimmunity $(3,4)$.

It is fascinating how this system discriminates between friends and foes to maintain homeostasis (5). 
Innate defenses are inborn abilities of the immune system to detect, attack, and eliminate (or at least restrain) pathogenic invaders. Part of the body's defense system that includes physical barriers (6), antimicrobial peptides (7), and complement proteins (8), innate immune cells are equipped with germline-encoded sensors called pattern recognition receptors (PRRs), which are predestined to recognize highly conserved molecular patterns including both pathogen- and damage-associated molecular patterns (PAMPS and DAMPs, respectively) (9, 10). Recognition of these molecular patterns allows for rapid host defense while "mostly" maintaining nonreactivity to self (thorough recognizing only PAMPs and DAMPs) $(9,10)$. This also paves the way for adaptive immune recognition that provides long-lasting immunity (11). Indeed, cellular components of the innate system, namely antigenpresenting cells (APCs) such as macrophages and dendritic cells (DCs) (12-14), as well as neutrophils (15), bridge the interface between innate and adaptive responses. APCs, in particular, play pivotal roles in informing their adaptive counterpart ( $\mathrm{T}$ and $\mathrm{B}$ lymphocytes) (16) for mounting antigen-specific responses with long-term memories that could also protect against future threats. The adaptive immune cells are highly antigen-specific $(17,18)$ and in a way to maintain self-tolerance, these cells cannot be activated solely by the initial recognition of antigen peptides through their somatically rearranged receptors ( $\mathrm{T}$ cell receptor and $\mathrm{B}$ cell receptor, or TCRs and BCRs, respectively); instead, their activation also requires costimulatory and cytokine signals in addition to antigen recognition (19-21). The co-stimulation signals ensure nonreactivity when encountering self-antigens, in which case peripheral tolerance (through deletion or anergy) would be induced (22-24). However, it is complicated how deviations would occur and specifically, how the breach of selftolerance and autoimmunity would develop.

According to the National Stem Cell Foundation, nearly 4\% of the world's population are affected by one or more autoimmune disorders; and as of 2019, the National Institute of Health estimated that around $7 \%$ of adults in the United States had been diagnosed with autoimmune conditions. Based on organ specificity and possible etiology, autoimmune disorders can be tissue-specific, such as type 1 diabetes (T1D), multiple sclerosis (MS), and autoimmune thyroid disease (AITD); or affect multiple organs, such as systemic lupus erythematosus (SLE), Sjogren syndrome, and rheumatoid arthritis (RA) (25).

Different theories have postulated various mechanisms for autoimmune inflammation including the breakdown of central and/or peripheral tolerance (reviewed elsewhere) (26, 27). Here, we summarize several possible mechanisms of immune dysregulation that could lead to systemic autoimmunity (Figure 1). These mechanisms include (1) defective apoptotic cell clearance (28), (2) defective apoptosis (29), and (3) loss of suppressive regulatory controls leading to hyperactivation of autoreactive T and B cells. We choose SLE to illustrate how these interrelated mechanisms of immune dysregulation drive autoimmune pathogenesis leading to tissue damage. SLE is a systemic autoimmune disease with a mortality rate nearly 3 times of that in the general population (30). There is no known cure so far.
Autoimmune disorders arise as a result of the interplay among diverse factors including genetic, epigenetic, and environmental triggers (31).

The link between genetic susceptibilities (or inherited anomalies) and the skewness from homeostasis to autoimmunity has been extensively reviewed (32-37). Notably, genetic susceptibilities are far more complex than a single genetic mutation and commonly manifested as multiple genetic susceptibilities.

Environmental factors can either potentiate or mitigate the effects of susceptibility genes, thereby having direct and indirect impacts on the development of immune tolerance and subsequent disease.

The association between environmental exposure and the development of human autoimmune disorders (38) supports the widely accepted notion that environmental triggers can program immune responses. For instance, early-life exposure to infections, vaccines (39), and dietary components (40) mold the immunological memory, consequently shaping how the immune system responds to exogenous stimuli later in life $(41,42)$. During the recent decades, the tremendous increase in the prevalence of autoimmune conditions coincides with evolving dietary and hygiene styles in Westernized societies (43), indicating a strong influence of environmental factors on autoimmunity (44-49). This is particularly important during pandemic eras since the emergence of unprecedented infections such as COVID-19 is thought to predominate among immunocompromised individuals such as those with preexisting autoimmune conditions who are also at an increased risk of COVID-19 related hospitalization (50). Indeed, autoantibodies against self-proteins such as type 1 interferons (IFNs) were found in cases of severe COVID infection and may account for COVID-19 deaths $(51,52)$. Interestingly, a recent report has found an increased pre-existing prevalence of anti-IFNo autoantibodies in SLE patients with COVID-19 infection compared to SLE patients without COVID-19 (53), suggesting that these autoantibodies might predispose SLE patients to contract COVID-19. Additionally, a recent study has shown that the activities of different exoproteome-directed autoantibodies (i.e., autoantibodies against immunomodulatory proteins such as cytokines, chemokines, complement components, and cell surface proteins) are dramatically increased in COVID-19 patients compared to uninfected controls (54). In parallel, murine surrogates of these autoantibodies have been shown to exacerbate disease severity in a mouse model of SARS-CoV-2 infection (54), suggesting autoimmunity as a driving factor for severe COVID-19. Together, these studies indicate that pre-existing autoimmunity put autoimmune patients at a higher risk for more severe COVID-19 infection and subsequent mortalities.

Conversely, it is believed that autoimmunity could be the comet tail following COVID-19 infection (54-56) especially in genetically predisposed individuals (57). Therefore, it is crucial to understand the influence of environmental factors on autoimmune regulation to better protect the more vulnerable populations during the COVID-19 pandemic. Specifically, this pandemic has witnessed some unprecedented shifts in human dietary habits both positively (e.g., increased consumption of domestically cooked foods, increased shares of plant-based diets) 


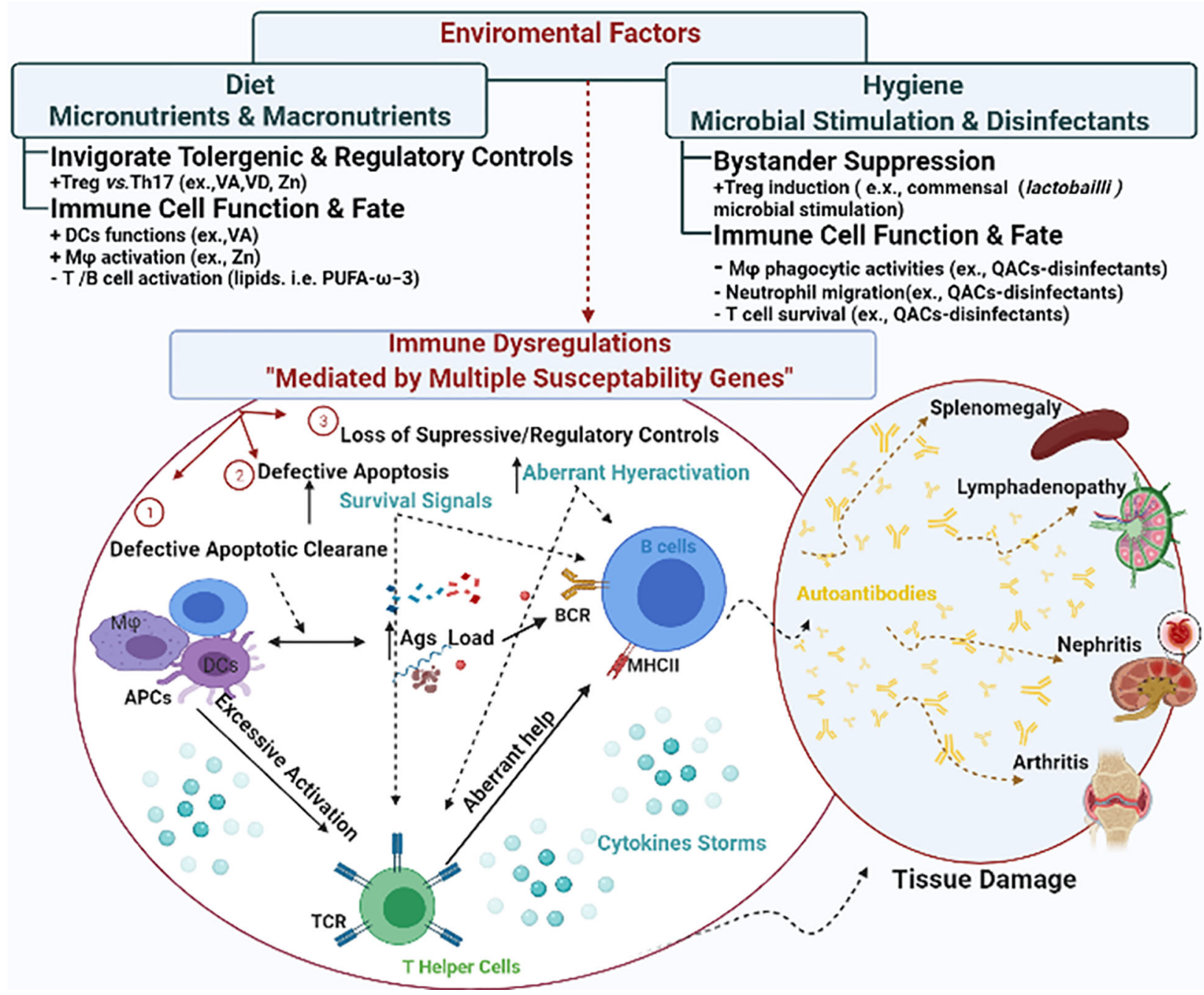

FIGURE 1 | The interplay between environmental factors and genetic susceptibilities in shaping immune dysregulation. Genetic susceptibilities could lead to immune dysregulation via different mechanisms including (1) defective apoptotic cell clearance, (2) defective apoptosis, and (3) loss of suppressive regulatory controls. Collectively they lead to disrupted cytokine signals and hyperactivation of autoreactive $T$ and $B$ cells, invigorating a series of tissue damage in various manifestations. In SLE, the manifestations could be presented as splenomegaly, lymphadenopathy, nephritis and arthritis. Environmental triggers either augment or mitigate these mechanisms to shape the autoimmunity.

and negatively (e.g., increased consumption of comfort food) (58). At the same time, people are advised to practice stricter hygiene measures $(59,60)$. Together these shifts in dietary and hygienic practices could on their own modulate our immune responses and/or autoimmune development or progression. In this review, we propose diet and hygiene as environmental regulators of immunity and discuss their influence on autoimmune development as depicted in Figure 1.

\section{Diet as an Environmental Factor}

Dietary practices can influence immune tolerance and disease. Indeed, dietary components, including micronutrients and macronutrients, can affect both innate physical defenses such as epithelial barrier integrity (61-64), antimicrobial peptides (65), and pro/anti-inflammatory cytokines (66-68), as well as adaptive immune cell functionality (69-72). The high incidence of immune-mediated diseases such as autoimmune and allergic disorders in the Western world, where common themes of dietary behaviors exist including increased caloric (fat and carbohydrate) intake with much less fibers and imbalanced dietary fatty acid consumption, pinpoint the immunomodulatory capacities of these macronutrients and their potential causal implications on autoimmune development (47). In contrast, dietary patterns that are mostly plant-based such as Mediterranean or DASH diets have been shown to contain anti-inflammatory and antioxidant components $(73,74)$ that could impose protective effects against autoimmunity (75). Among these, plant-derived phytochemicals including polyphenols (76) such as flavonoids (77-79) and isoflavones $(80,81)$ have been extensively investigated for healthful modulation of autoimmunity. 
To this end, the upside of the COVID-19 pandemic is its impact on the unprecedented dietary shifts to less processed and more plant-based dietary sources (82). Interestingly, plant-based diets are associated with lower odds of moderate-to-severe COVID-19 and may provide protective support against severe COVID-19 infection (83). Indeed, such dietary trends with COVID-19 emergence can not only benefit to restrain COVID-19 infection in normal people but also be supportive strategies for the vulnerable populations with autoimmune conditions. For example, quercetin is a natural flavonoid derived from different plant sources that has various antiinflammatory and antioxidant immunomodulatory capacities $(84,85)$. Based on pharmacology and molecular docking, quercetin has been proposed as a potential protective treatment against acute renal injury, one of the most serious complications reported in hospitalized patients with COVID-19 infection (86-88). At the same time, quercetin has been shown to attenuate various autoimmune pathologies in human and murine rheumatoid arthritis (RA) (89-92), and in experimental models of inflammatory bowel diseases (IBD) $(93,94)$ and SLE $(95)$. In the following section, we review how different micronutrients and macronutrients modulate immune health and autoimmune outcomes and discuss the potential advantageous roles of dietary manipulation in mitigating the risks of COVID-19 infection in autoimmune patients.

\section{MICRONUTRIENTS AND AUTOIMMUNITY}

Micronutrients including vitamins (such as vitamins E, A, and D) and minerals (such as selenium, copper, and zinc) are long known to possess capabilities to modulate immune responses. Micronutrients can tone every aspect of both innate and adaptive responses (96). In the following section, we will discuss the role of vitamins and minerals in maintaining health and how their deficiencies contribute to autoimmune diseases.

\section{Vitamins}

Vitamins have important functions in maintaining immune health through their antioxidant capacities (97). There is a huge body of literature supporting the notion that oxidative stress plays a crucial role in autoimmune pathogenesis (98-100). For instance, oxidative degradation of lipids that occur in the cellular membrane in a process known as lipid peroxidation is mediated by free radicals $(101,102)$, which could impair the integrity of the cell membrane (103), induce cellular death (101) and accumulate apoptotic products, subsequently initiating autoimmunity (104-106). In addition, intracellular oxidative signaling could increase the responsiveness of autoreactive immune cells such as $\mathrm{T}$ lymphocytes and drive their autoimmune pathogenicity (107). Moreover, the extracellular release of oxidative products including reactive oxygen species (ROS) and proteases by innate immune cells such as neutrophils could initiate autoreactivity and lead to collateral tissue damage (108). Interestingly, oxidative stress has also been proposed to be associated with COVID-19 pathogenesis (109-111). Therefore, antioxidant vitamins could provide potentially beneficial supportive care for autoimmune patients with COVID-19. Here, we review the immunomodulatory functions of vitamins $\mathrm{E}, \mathrm{A}$, and $\mathrm{D}$ in autoimmunity and discuss their potential implications in COVID-19.

Vitamin E (VE) as an antioxidant can diminish the secretion of ROS (e.g., by monocytes) (112), thereby protecting against oxidative cell stress and indirectly maintaining immune cell functionality. Therefore, it has been suggested that the relative deficiency of VE could initiate autoimmunity (113). Although data from human studies are not conclusive-where some reports showed that VE levels were increased in patients with systemic autoimmunity of primary Sjögren's syndrome (114), while others correlated VE deficiency with the development of neurological complications of celiac disease (115) or showed no difference in VE levels in patients with IBD (116)-murine studies more decisively support the potential beneficial effect of VE in the treatment of autoimmune conditions such as RA (117, 118). Importantly, based on data from murine lupus, VE is proposed as a safe treatment option for $\operatorname{SLE}(119,120)$ where the supplementation reduces hallmarks of SLE such as the levels of anti-double-stranded DNA (anti-dsDNA) IgG antibodies (121) and counteracts oxidative stress (and lipid peroxidation) that would otherwise contribute to more debilitating SLE manifestations $(122,123)$. In human studies, VE supplementation as part of a treatment regime improved the oxidative and nitrosative biomarkers and disease activity in SLE patients (124).

Vitamins A and D (VA and VD, respectively) are known to modulate the differentiation of immune cells, their tissue homing, and effector functions. On the innate arm, VD and VA have context/tissue-dependent functions that may antagonize each other. VD has been shown to mitigate the maturation of DCs, inhibiting their expression of maturation markers MHCII and CD80/86 (125), as well as reducing their production of the proinflammatory cytokine IL-12 (126), collectively inducing the tolerogenic phenotype of DCs $(127,128)$. In contrast, VA has context-dependent effects on DCs. Although VA is a key player in the induction of mucosal tolerance (129), it can also enhance DC maturation and their antigen-presenting capacities in the presence of pro-inflammatory stimuli (130). In addition, VA can increase the expression of matrix metalloproteinase-9 (MMP9) to enhance the migration of inflammatory DCs to lymph nodes (131). Together, these immunomodulatory capacities of VD and VA could represent a tango for in-vivo tuning of DC functions. Importantly, since DCs could modulate self-tolerance and the development of autoimmune disease such as SLE as we previously reviewed (132), VD (133)-, and VA (134, 135)-mediated regulation of DC function could indirectly impact the development of tolerance and disease. On the adaptive arm, both VD and VA can affect the differentiation of T cell subsets, including $\mathrm{T}$ helper (Th)1 (proinflammatory) vs. Th2 (antiinflammatory), and $\mathrm{T}$ regulatory (Treg; immunosuppressive) $v s$. Th17 (proinflammatory) as depicted in Figure 2. For example, VD $(67,125,136-138)$ and VA (139-141) have been shown to inhibit Th1 differentiation and responses while supporting the 


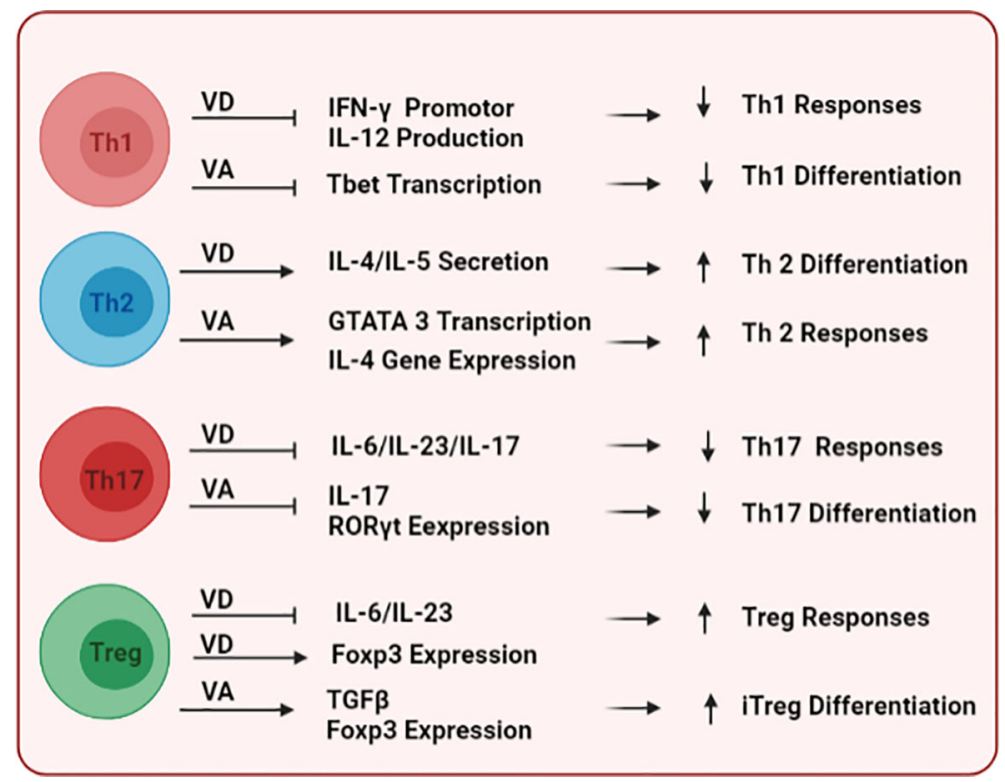

FIGURE 2 | The immunomodulatory effects of vitamins D and A on T cells. Following their binding to DNA responsive elements of target genes, both vitamins differentially modulate key transcription factors and stimulatory cytokine signals to shape the commitment and functional responses of multiple T-cell subsets including Th1, Th2, Th17, and Treg.

development and responses of Th2 lymphocytes. In addition, both VD $(142,143)$ and VA (144-146) potentiate the development of Treg over Th17. Importantly, the imbalance between these different $\mathrm{T}$ cell subsets is a driving force for autoimmune development $(147,148)$.

Ecological associations between low VD levels and the incidence of different autoimmune conditions such as IBD, MS, T1D, and RA have been reported in areas with limited sun exposure (149-151). It is widely hypothesized that deficiency of VD is associated with the development of different autoimmune conditions where polymorphism in VD receptors (VDR) are implicated among the causal risks for autoimmune conditions including AITD (152, 153), T1D (154), MS (155), RA (156) and SLE (157). In addition, VD deficiency is associated with more aggravated autoimmune flares in SLE (158-161) by promoting memory B cells responses (162) and subsequent autoantibody production (163). These observations strengthen the potential use of VD supplementation to control autoimmune disease (164). Importantly, plasma (165) and serum (166) levels of VD have been shown to be depleted in COVID-19 patients. Additionally, low levels of VD are also correlated with the severity of COVID-19 progression in those patients (166). Meanwhile, VD supplementation during or just before COVID-19 contraction can mitigate disease progression and enhance the survival rate in infected patients (167). Together these reports support the potential healthful effect of VD in autoimmune patients to combat COVID-19 severity and fatality.

In contrast, it remains to be determined if VA deficiency or polymorphisms in VA receptors are causally associated with autoimmune development. Although serum retinol levels have been negatively correlated with MS activity (168), and hypovitaminosis A has been detected proceeding the clinical diagnosis of SLE $(169,170)$, it is still to be elucidated whether VA deficiency is a driving factor for autoimmunity. Due to their immunomodulatory capacities, retinoids have been proposed as potentially beneficial adjuvants controlling autoimmune disorders (171). The most active metabolite of VA, all-trans-retinoic acid (tRA), has been shown to control pathogenic T cell subsets such as IL-17 secreting $\gamma \delta$ T cells and sufficiently ameliorate experimental autoimmune encephalitis (EAE), a murine model of MS. Similarly, we and others have shown the protective effects of VA on murine SLE especially during the active stage of the disease (172-174). In future investigations, we propose to (1) investigate the potentially detrimental effects of VA deficiency on the progression of renal inflammation in genetically-prone SLE, and (2) delineate the molecular and transcriptional mechanisms by which hypovitaminosis A promotes systemic autoimmunity. Importantly, a recent study conducted in hospitalized COVID19 patients with respiratory failure showed that serum retinol levels were significantly lower compared to healthy controls (175). This report's findings support the idea that COVID-19 infection is associated with retinoic acid depletion syndrome (176) and that VA supplementation might be a beneficial approach especially in areas of limited medical resources (177). Therefore, considering its complex roles in modulating autoimmunity, VA might be a crucial element to be considered for monitoring and supplementation as needed for autoimmune patients with COVID-19 infection.

It is important to note that for clinical applications, optimal levels of these vitamins as combinations may be crucial for 
achieving the harmony of their action. Future investigations on the vitamins' modulation of autoimmunity as an overlapping circuit rather than solo-induced effects will shed more light on their therapeutic potential in clinical settings.

\section{Minerals}

Minerals, or specifically trace elements such as selenium, copper, and zinc, modulate immune functions in various indirect ways. Generally, minerals can have antioxidant capacities and consequently maintain the structural integrity of essential biological molecules (e.g., maintaining cell membrane stability) (178), participate in enzymatic activities (179), and potentiate energy production and use during cellular metabolism (180). Importantly, some trace elements are needed to facilitate cell signaling $(181,182)$, where their binding to target ligands/ receptors regulates essential processes including gene expression and protein synthesis $(183,184)$. Selenium, for example, acts as an antioxidant, eliminating free radicals and subsequently maintaining immune system functions (185). It also has catalytic activities and is essential for the enzymatic activity of glutathione peroxidase to inhibit lipid peroxidation (186). This is particularly important for protecting cell membrane phospholipids, consequently maintaining cell membrane structure and preventing oxidative mitochondrial damage in immune cells such as macrophages (187-189). Therefore, selenium deficiency is associated with increased inflammation $(190,191)$ and autoimmunity as in celiac disease and AITD (192). Similarly, meta-analysis of genome-wide association studies (GWAS) have predicted high selenium levels to be associated with a decreased risk for SLE (193). Indeed, selenium supplementation in murine models of SLE has been shown to improve survival (194) and mitigate various hallmarks of the disease including splenomegaly and autoantibody production (195). In addition, a recent cohort study has shown that severe COVID-19 patients exhibit a pronounced deficit in total serum selenium and selenoprotein levels, and that selenium status is significantly higher in COVID survivors compared to non-survivors, suggesting the therapeutic potential of selenium supplementation in severely diseased and/ or selenium-deficient COVID-19 patients (196).

Aside from these non-specific immunomodulatory capacities, minerals can directly modulate both innate and adaptive immune cell activities and be involved in the activation of key signaling molecules such as NF- $\kappa \mathrm{B}$. Zinc, for example, can be both pro- and anti-inflammatory and plays an essential role in maintaining both innate and adaptive cellular responses (197). Zinc promotes NF- $\kappa \mathrm{B}$ signaling and subsequently the production of pro-inflammatory cytokines from macrophages $(198,199)$. The utilization of zinc by macrophages enhances their phagocytic activities (200, 201). Therefore, lower circulatory levels of zinc could be linked to macrophage-related autoimmune diseases such as RA (202). Meanwhile, zinc can also induce tolerogenic DCs in both in-vivo and in-vitro settings (203). Thus, zinc deficiency could compromise the interface between innate and adaptive immunity leading to skewing of Th cell balance (203). Zinc is essential for T lymphocyte proliferation (204) and activation (205) through promoting
IL-2 signaling. It also promotes the upregulation of IL-12 signaling and Th1 transcription regulator T-bet (206). Consistently, zinc deficiency reduces the levels of Th1polarizing cytokines (e.g., IFN $\gamma$ ) (207). Therefore, a shift of Th1/Th2 balance to Th2 has been linked to zinc deficiency. However, zinc can enhance the differentiation of Treg cells through upregulating FOXP3, where it increases the phosphorylation of Smad proteins, allowing for its binding to the Foxp3 promoter (208). Furthermore, zinc can suppress Th17 differentiation through inhibiting signal transducer and activator of transcription 3 (STAT3) signaling (209) as well as memory Th17 responses via inhibition of the IL-1 $\beta / \mathrm{IL}-1$ receptorassociated kinase 4 (IRAK4) phosphorylation (210). Thus, zinc can benefit by tuning $\mathrm{T}$ cell-driven autoimmunity as shown in EAE $(211,212)$. In human studies, lower systemic zinc levels have been reported in different autoimmune conditions (213) including MS (214) and SLE $(215,216)$. Interestingly, COVID-19 patients also have lower zinc levels that are correlated with disease complications and prolonged hospital stays (217). Together, these studies warrant further investigation on the immunomodulatory capacities of zinc in autoimmune and/or other high-risk patients for COVID-19.

In summary, micronutrients are essential for fine-tuning the development and function of immune cells. Altered homeostasis of micronutrients as seen in various autoimmune diseases could critically influence immunity and promote autoimmune dysregulations.

It is noteworthy that although evidence-based findings are still being uncovered on the causal relationship between micronutrient deficiencies and more severe COVID-19, as well as the potential healthful effects of micronutrients on COVID convalescence, the immunomodulatory functions of micronutrients may support their roles in combating COVID19 infection (218-220). Therefore, for autoimmune patients in the COVID-19 pandemic, the potential benefits of micronutrients as discussed above urge for regular monitoring of their levels and if deemed necessary, supplementations in individuals with specific micronutrient deficiencies.

\section{MACRONUTRIENTS AND AUTOIMMUNITY}

Macronutrients have diverse immunomodulatory functions that dynamically modulate immune cell responses to shape autoimmune outcomes. Data exploring the implication of specific macronutrients in COVID-19 are lacking. However, it is well established that overconsumption of energy-yielding macronutrients could lead to obesity (221), a condition considered as one of the major risk factors of severe COVID-19 infection (222-225). Here, we review current knowledge on the modulation of autoimmunity by different macronutrients and discuss points to be considered with regards to COVID-19 infection in autoimmune patients.

\section{Carbohydrate, Fat, Protein}

Dietary carbohydrates are usually in the form of polysaccharides, oligosaccharides (e.g., fructo-oligosaccharides), disaccharides 
(e.g., lactose), and monosaccharides (e.g., glucose and fructose) (226). Carbohydrates, especially non-digestible polysaccharides and oligosaccharides (e.g., in prebiotics), exert both direct and indirect immunomodulatory capacities. Indirectly, they act as a source of energy for gut microbiota which, in turn, could modulate immune responses via different mechanisms as previously reviewed $(227,228)$. Directly, they could modulate both innate and adaptive effector immune functions involving epithelial tight junctions, cytokine/chemokines, and antibody production as reviewed elsewhere (229). Indeed, dietary polysaccharides are sensed by different immune cell receptors including complement receptor 3 (CR3), Toll-like receptor (TLR) as well as dectins (carbohydrate-binding proteins) (230); subsequently, they act as immunogens to stimulate immune responses. Notably, plant polysaccharides can be the interface linking innate and adaptive immune cell activation. They primarily stimulate the proliferation and activation of innate cellular components such as natural killer (NK) cells (enhancing their cytotoxic activities) and macrophages (augmenting their production of TNF $\alpha$ and IL-6 as well as their lysosomal activities and nitric oxide production) (231). In turn, these innate components activate their adaptive counterparts, inducing Th cell differentiation and antibody production from $\mathrm{B}$ cells as previously detailed (231).

The effector functions of immune cells rely primarily on glucose (232). Therefore, it is not surprising that high carbohydrate intake could exacerbate the hyperactivation of immune cells in chronic inflammatory and autoimmune conditions. Indeed, modern diets containing high levels of processed fructose-rich carbohydrates increase the incidence of chronic inflammation $(233,234)$. High glucose intake augments ROS-dependent activation of TGF $\beta$ and consequently the induction of Th17, thereby exacerbating autoimmune conditions as reported in murine models of MS (i.e., EAE) and colitis (235). In addition, excessive carbohydrate intake increases the levels of circulatory inflammatory markers such as IL-6 and C-reactive proteins (CRP) in SLE patients (236). In contrast, natural glucose derived from plant-based carbohydrates such as cell wall-based cellulose (which is an insoluble fiber and composed of unbranched $\beta$-1,4-linked glucose monomers) has been shown to reduce the frequency and number of proinflammatory $\mathrm{T}$ cells and promote autoimmune suppressive Th2 responses in EAE (237). These findings illustrate the pivotal effects of dietary carbohydrates on immune cell functions and warrant further investigations towards more mechanistic insights with a specific emphasis on autoimmune modulation.

It is also crucial to maintain a balance between carbohydrates and other macronutrients including dietary fats and proteins. Although plant-based lipids (e.g., phytosterol from vegetable oils) could beneficially modulate autoimmune inflammation as reported in $\operatorname{EAE}(238,239)$, it is controversial how fat-modulated diets precisely shift immune responses and subsequently autoimmune progression. If only the level of fat consumption is changed, reduced dietary fat levels increase the proliferation of human peripheral blood mononuclear cells (PBMCs) following both mitogens and inflammatory cytokine stimuli (240), suggesting better responses to pathogenic invaders (241). However, recent studies propose that ketogenic diets of low carbohydrate and high fat intake potentiate more protective $\gamma \delta \mathrm{T}$ cell responses against infectious triggers (242). This emphasizes the importance of considering the levels of all macronutrients together when assessing immune modulation under steadystate conditions.

Under autoimmune conditions, on the other hand, a large pool of evidence proposes that a high-fat diet (HFD) adversely impacts the immunopathogenesis of different autoimmune diseases as widely investigated in SLE (243). For example, high fat intake resulted in defective phagocytic and cytotoxic activities of macrophages and NK cells, respectively, and this was associated with earlier onset and exacerbated autoimmunity in lupus-prone NZB/W F1 mice (244). In addition, HFD further increased TLR7 expression and signaling in TLR8 knockout mice (a spontaneous murine lupus model characterized by increased TLR7 signaling) leading to exacerbated kidney inflammation due to increased production and renal deposition of autoantibodies (245). Furthermore, HFD-induced obesity increased the $\mathrm{T}$ follicular helper ( $\mathrm{Tfh}$ ) cell activity in MRL/lpr mice and consequently the activation of $B$ cells, exacerbating SLE-associated splenomegaly and potentiating IgG production and their glomerular deposition (246). In contrast, a low-fat, isoenergetic diet designed to provide no more than $20 \%$ energy from fat a day, together with supplementation of $1 \mathrm{~g}$ of fish oil, effectively attenuated disease activity in SLE patients (247). Although it is yet to be tested whether high fat/low carbohydrate ketogenic diets are beneficial in SLE patients, a potential positive effect of ketogenic diets has been reported for some autoimmune patients with MS (248) or T1D (249). Interestingly, a ketogenic diet may also provide supportive care for COVID-19 patients (250), reducing their need for the intensive care unit (251). This again emphasizes the importance of considering the levels of all macronutrients together on immune modulation under autoimmune status and highlights the importance of personalized care plans for autoimmune individuals with COVID-19 infection.

Not only the quantity but also the type of consumed fat could differentially affect the immunopathogenesis of autoimmunity. Dietary fats could be in the form of saturated fat, trans-fat and unsaturated fat. Increased intake of saturated fat accelerates the disease relapse in children with MS (252). Increased consumption of trans-fat increases the levels of free radicals that damage the integrity of immune cell membranes and contribute to autoimmunity (243). In contrast, the incorporation of Mediterranean diets that significantly increases the ratio of unsaturated to saturated fats has been linked to improved autoimmune pathologies (e.g., alleviating RA symptoms) (253). Notably, a diet rich in polyunsaturated fatty acids (PUFA) can improve the overall clinical scores and elicit anti-inflammatory effects in SLE (254). Similarly, a recent report has shown a negative correlation between adherence to Mediterranean diets and COVID-19 cases in Spain and other countries (255), supporting a potential protective role of PUFArich Mediterranean diets against COVID-19 $(256,257)$. 
Indeed, supplementation of PUFA such as omega-3 $(\omega-3)$ augment the activities of antioxidant enzymes and diminish autoimmunity (243). Several studies have shown that $\omega-3$ enriched diets dramatically reduce SLE-associated inflammatory markers, lupus progression (mitigating glomerulonephritis) and improve survival in different mouse models of SLE (258-262). This is achieved mostly through potentiating the effects of antioxidant enzymes (such as superoxide dismutase and glutathione peroxidase) which, in turn, potentiate the ability of renal cells to eliminate harmful free radicals (e.g., reactive oxygen intermediates) $(259,261)$. Moreover, a diet rich in $\omega-3$ (e.g., with fish oil) reduces the level of anti-dsDNA antibodies $(258,261)$, circulating immune complexes, and their renal deposition (258). Furthermore, fish oil can reduce the expression of renal pro-inflammatory cytokines including IFN $\gamma$, IL-12, TNF $\alpha$ (259, 261), and renal profibrotic molecules such as TGF $\beta$ and fibronectin-1 (261). By downregulating these molecules, fish oil diminishes the ageassociated activation of NF- $\kappa \mathrm{B}$ signaling in lupus mice, thereby mitigating lupus nephritis (259). Indeed, fish oil is a dietary source for $\omega-3$ PUFA that exerts anti-inflammatory capacities through dampening immune cell responsiveness to IFN $\gamma$ (263). Recent findings have shown that $\omega-3$ PUFA could also downregulate biomarkers associated with $\mathrm{T}$ and $\mathrm{B}$ cell activation and/or differentiation and leukocyte recruitment such as CD80, CTLA-4, IL-18, CCL5, CXCR3, IL-6, TNF $\alpha$ (264). Similarly, they mitigate inflammatory markers associated with intestinal inflammation/colitis such as IL-6, inducible nitric oxide synthase (iNOS), cyclooxygenase-2 (COX-2), and leukotriene $\mathrm{B}_{4}\left(\mathrm{LTB}_{4}\right)$ (265). Collectively, these beneficial actions of $\omega$-3 PUFA on autoimmune development (especially SLE) could be targeted in future human intervention studies. Interestingly, for their immunomodulatory capacities, $\omega-3$ PUFA have been recently proposed as part of the supportive care for COVID-19 patients $(266,267)$, as recent pilot data suggest that a higher $\omega-3$ index may lower the risk of COVID-19 fatality (268). Therefore, diets rich in PUFA might confer benefits for autoimmune patients with SARS-CoV-2 infection.

Dietary proteins are the third component of macronutrients in a balanced diet and are hydrolyzed in the gut to generate amino acids and peptides. Proteins can, directly and indirectly, modulate immune functions. Directly, dietary proteins-derived amino acids can serve as major energy sources for leukocytes, enhance the development of immune cells from hematopoietic progenitors, and modulate their effector functions as previously reviewed (269). Indirectly, proteins are utilized through gut microbiota which in turn mediates the interplay between protein metabolites and the host immune system as detailed elsewhere (270). Indeed, exposure to dietary protein antigens is necessary for the maturation of the immune system $(271,272)$. Feeding of weanling mice a protein-deficient diet that had only free amino acids resulted in a poorly developed immunological profile that resembled that of newborn or germ-free (GF) mice $(271,273)$, which is characterized by reduced secretory IgA and systemic Ig levels as well as less-developed gut-associated lymphoid tissues $(271,273)$. Moreover, in addition to playing an integral role in the development of oral tolerance $(273,274)$, early-life intake of protein antigens is crucial for Th1 differentiation (271), B cell responses, and class switching (275), thereby helping to augment the immunity against infectious invaders later in life (272). Together, these studies suggest that dietary protein malnutrition (PM) could adversely impact immunity. Interestingly, both PM and excessively high protein intake could exacerbate inflammation. PM could potentiate intestinal mucosal damage following inflammatory stimulation (e.g., zymosan-induced systemic inflammation), allowing bacterial translocation and gut-induced septicemia (276). In parallel, in contrast to proteins from plant origins that could mitigate inflammation (277), a high-protein diet, especially from animal origin, aggravates both acute and chronic dextran sulfate sodium (DSS)-induced colitis via promoting the pro-inflammatory responses of macrophages (278). Furthermore, high protein intake has been associated with deterioration of renal disease involving glomerular hyperfiltration (279). Meanwhile, a low-protein diet could help the management of chronic kidney diseases (280). As kidney inflammation, namely lupus nephritis is the most lifethreatening manifestation of SLE, modulation of protein intake could be of great importance. Indeed, moderate dietary protein intake of $0.6 \mathrm{~g} / \mathrm{kg}$ daily improves renal functions in SLE patients (281). Restriction of protein intake in NZB/W F1 mice improved the disease outcome, inhibited splenomegaly, and maintained immune cell responsiveness to mitogenic stimulation (282).

Together, these observations suggest that dietary protein modulation can influence immune components in the pathogenesis of autoimmune disorders such as SLE, therefore warranting further studies to elucidate the underlying cellular and molecular mechanisms.

\section{Energy Intake}

Epidemiological association between obesity and autoinflammatory disorders (283) suggests that excessive caloric/energy intake could lead to the breakdown of immunological tolerance. Excess caloric intake in early life increases the incidence of IBD (284) and autoimmune thyroiditis (285) in adulthood. In contrast, caloric/ energy intake restriction (EIR) can improve the autoimmune/ inflammatory outcomes as have been reported in experimental models of SLE (286-291), EAE (292-295), and Sjogren's syndrome (296).

Immune responses are high energy-dependent to fuel the biosynthetic needs of activated immune cells. The bioenergetic demand of immune cells is achieved via three interconnected metabolic pathways including oxidative phosphorylation (which occurs in the mitochondria of naïve cells), glycolysis (which occurs in the cytoplasm of activated and proliferating cells), and tricarboxylic acid (TCA) cycle (which occurs in the mitochondria of activated and proliferating cells) (232). The immune system is dynamically active with continuous changes in cellular activities such as those between resting naïve cells and proliferating effector cells, and those of memory/long-lived cell populations that might be quiescent but ready to undergo rapid proliferation upon stimulation. Therefore, the cellular energy 
demand is variable based on the phases and activities of immune cells (297-299). For instance, for a cell in a resting state (e.g., naïve $\mathrm{T}$ or $\mathrm{B}$ cells), the need for energy will be towards maintaining its minimal metabolic and biosynthetic requirements that are directed for building cellular components. Therefore, the cellular energy expenditure is met through oxidative phosphorylation and targets preserving cellular integrity. In contrast, effector immune cells undergo rapid proliferation and have a wide range of effector functions as represented in the production of effector molecules such as cytokines, chemokines, inflammatory mediators, and immunoglobulins. This will require upregulation of fuel uptake and aerobic glycolysis to satisfy higher metabolic configurations needed for both bioenergetic and biosynthetic pathways (297299). Importantly, these shifts of cellular energy phases could be largely dependent on nutrient and energy supplies in the microenvironment. Moreover, energy/caloric intake can influence cellular metabolism as well as phenotypic and functional capacities of immune cells (300-302). For instance, due to chronic metabolic stress leading to ATP depletion, chronically activated $\mathrm{T}$ cells in SLE patients fulfill their need for ATP through oxidative phosphorylation rather than upregulating the aerobic glycolysis (303). In parallel, continuous low-grade inflammation due to excess energy intake (as in obesity) exacerbates the proinflammatory phenotype of different immune cells, favoring the differentiation of Th1 and Th17 subsets while diminishing the frequency of Treg cells (304), thereby predisposing individuals to autoimmunity (283).

Furthermore, energy intake can shape the fate of immune cells (e.g., differentiation and effector functions) through modulating key signaling pathways and transcription factors which in turn contribute to autoimmune pathogenesis. For instance, activation of $\mathrm{T}$ cells through TCR signaling and CD28 co-stimulation leads to activation of the phosphatidylinositol-4,5-bisphosphate 3-kinase (PI3K)/Akt pathway (305-307), which subsequently turns on the mammalian target of rapamycin (mTOR) pathway, where mTOR is of two functional complexes, mTORC1 and mTORC2 (308). mTOR is a central regulator for $\mathrm{T}$ cell differentiation and homeostasis $(309,310)$. Under normal nutrient and energy conditions, mTOR (especially mTORC1) senses the microenvironment and upregulates the expression of glycolytic genes (311), allowing for biosynthetic anabolic processes needed for cell proliferation (309). However, excessive functions of mTOR can disrupt cellular differentiation and predispose individuals to autoimmune conditions such as RA (312) and SLE (313). Augmented mTOR activities under autoimmune conditions are not limited to $\mathrm{T}$ cells, where mTORC1 expands pathogenic $\mathrm{T}$ cell populations including Th17 and the $\mathrm{CD} 4^{-} \mathrm{CD} 8^{-}$doublenegative T (DN-T cells) while suppressing Treg cells (313); but also B cells (314-316), DCs and macrophages $(317,318)$. Activation of mTORC1 precedes the onset of SLE as a result of chronic metabolic stress with long-term ATP depletion and mitochondrial hyperpolarization $(319,320)$. In contrast, during energy restriction, rapid inhibition of mTOR occurs, allowing the shift to catabolic processes to maintain the energy required for cell survival $(321,322)$; at the same time, Treg cells become responsive to TCR stimulation, thus enhancing their proliferation (323). Therefore, optimizing the cellular metabolic shifts could open new therapeutic avenues for the treatment of autoimmunity $(324,325)$.

Consistent with this notion, EIR can suppress the immunopathogenic responses associated with autoimmunity and chronic inflammation including hyperactivation of cellular and humoral responses (326). For instance, EIR reduces antigen processing by macrophages as well as the $\mathrm{T}$ cell-dependent activation of B cells (326). Similarly, EIR diminishes the inflammatory activities of circulating monocytes and their mobilization from the bone marrow without compromising their emergency egression during acute infection and tissue repair (327). Through these mechanisms, EIR has been shown to modify the autoimmune/inflammatory pathogenesis of various disorders (286-296). For example, EIR can dampen the SLE progression. Early dietary modulation through caloric restriction by the time of weaning reduces SLE-associated lymphadenopathy in mice (328). Caloric restriction significantly reduces $B$ cell frequencies and their activation (291), reduces circulatory anti-dsDNA antibodies, and prevents the increase of possibly pathogenic $\mathrm{T}$ cell subsets such as DN-T cells (329), while maintaining a higher percentage of naïve $T$ cell subsets (291) as well as the responsiveness of lymphocytes to mitogenic stimulation (329). In addition, lupus-prone NZB mice with chronic energy/calorie intake restriction (CEIR; fed a $40 \%$ caloric reduction diet that was relatively low in fat and high in carbohydrates) prolongs the survival and delays the disease initiation (286). In NZB mice as well as other lupus-prone murine models including MRL/lpr and BXSB, CEIR diminishes proliferation of lymphoid cells in the spleen, thymus, and mesenteric lymph node (MLN) (287), downregulates the transcript levels of proinflammatory cytokines such as IFN $\gamma$ and IL-12, reduces IgA and IgG2a autoantibodies (288), and decreases molecules associated with fibrinogenesis such as platelet-derived growth factor (PDGF) (289), subsequently ameliorates lupus-associated kidney inflammation or glomerulonephritis. These observations emphasize the potential use of EIR in the treatment of SLE.

In summary, calorie restriction (e.g., intermittent fasting) and fat/carbohydrate modulation (e.g., ketogenic diets) may provide novel opportunities against autoimmunity by regulating both adaptive and innate immune activation pathways (242, 330). However, further studies are warranted to establish the safety and clinical efficacy of immunometabolic treatment strategies in autoimmunity. In parallel, it is essential to ensure that the modulated diets do not lead to malnutrition that promotes immune dysfunction and increases the risk and severity of infections (331). Notably, malnutrition predisposes COVID-19 patients to more severe disease in an age-dependent manner (332) and increases the odds of their fatality (333). Indeed, COVID-19 patients may require higher energy intake and increased protein consumption (334), and it is a necessity to 
consider the immunomodulatory influence of macronutrients for proper supportive managements of autoimmune patients with COVID-19 infection.

In Table 1, we present a short list of several nutrients that have shown beneficial effects in murine models of SLE where human studies are warranted.

\section{HYGIENE AS AN ENVIRONMENT FACTOR}

According to the hygiene hypothesis, microbial stimulation might be particularly crucial for immune education during early life, leading to less self-reactivity, thereby mitigating the development of autoimmunity later in life. This might be conceivable since both neonatal innate and adaptive defenses are biased towards maintaining tolerance developed in utero (as reviewed elsewhere) $(341,342)$. For instance, neonatal APCs have reduced antigen-presenting and costimulatory capacities (343, 344). Similarly, neonatal $\mathrm{T}$ cells have a default programming toward a Treg phenotype (345) and exhibit more bias toward Th2 cell responses (346). Together, these evidences could explain the increased susceptibility to infections and higher disease morbidity in neonates (347). Interestingly, challenging the neonatal defenses with infections reshapes their immune responses (348) and could modulate responses during inflammatory and autoimmune processes later in life (349). Indeed, besides the interaction with dietary antigens (as we discussed above), early-life maturation of the immune system and the development of immunological tolerance are achieved through immense pressure from microbial stimulation in our surroundings $(349,350)$, where microbial influences create a balance between protection and tolerance (351). For instance, commensal microbial colonization limits the expansion of pathogenic/disease-causing pathobionts $(352,353)$, and more importantly, colonization of commensal microbes early in life can induce Treg cells on mucosal sites (such as the lungs) and subsequently promote homeostasis and tolerance later in life $(354,355)$. In contrast, microbial depletion or reduced microbiota diversity [e.g., through antibiotic treatment early in life (356)] can have long-term immunological consequences $(357,358)$, where the lack of microbial diversity during the neonatal stage could lead to a higher incidence of chronic inflammatory and topical disorders later in life (359).

Cases of hyperinflammatory responses that could fit within the criteria for autoimmune disorders have been reported following COVID-19 infections (360-366). This leads us to the question of whether the viral infection itself could contribute to the breakdown of self-tolerance. It is widely accepted that infections could trigger autoimmunity (367-372). Mechanisms of such include (1) bystander activation of innate cells enhancing the presentation of self-antigens and thereby the expansion of autoreactive adaptive counterparts, (2) release of autoantigens, neoantigen formation, and epitope spreading following excessive tissue damage, thus promoting autoimmunity, and (3) induction of molecular mimicry or cross-reactivity when both infectious/ exogenous antigens and self-antigens share sequence or structural similarities leading to autoreactivity against self (367, 373). In this regard, although data are still needed on the ability of SARS-CoV-2 to induce bystander activation and neoantigen formation, the non-specific activation of innate immune cells generating a wide array of pro-inflammatory cytokines (e.g., cytokine storms) following COVID-19 infection (374) may lead to tissue damage and generation of neoantigens or epitope spreading, thus initiating autoimmunity. Consistent with this notion, it was previously reported that in severe acute respiratory syndrome-associated coronavirus (SARS-CoV) infection, the presence of cross-reactive epitopes on SARS-CoV spike protein domain 2 could generate antibodies that also cross-reacted with epitopes on lung epithelial cells (375). Similarly, recent reports have shown that based on transcriptomic analysis, SARS-CoV-2 shares molecular similarities with diverse human central nervous system (CNS) protein epitopes that could trigger CNS autoimmunity (376).

On the other hand, infections could be a double-edged sword where different hypotheses exist on how infections could modulate autoimmunity. As postulated by the hygiene hypothesis, infections could counteract autoimmune development and represent a therapeutic intervention against autoimmunity. Notably, there are compelling evidences that specific pathogens suppress different autoimmune conditions in murine models of SLE (377), CNS autoimmunity (378) and T1D (379). Generally, the potential mechanisms that might explain the protective influence of infections on autoimmunity [as reviewed by others (44)] include (1) antigenic competition where a strong immune response is induced by a stronger antigenic stimulus from an infectious agent competes on signals of inflammation (e.g., pro-inflammatory cytokines) with a weaker signal from autoantigens leading to dampened responses towards the weaker stimulus (380), (2) desensitization of antigen recognition receptors such as TLRs due to repeated low-dose antigenic stimulation leading to anergic responses to autoantigens (381-384), and (3) induction of immunosuppressive phenotype or bystander suppression where infectious agents enhance the signaling that rebalances the regulatory to pro-inflammatory $\mathrm{T}$-cell subsets by increasing the Treg cells and limiting Th17 expansion (385).

Furthermore, based on the hygiene hypothesis, or the microbiome depletion theory, there is a positive epidemiological association between the increase of countermeasures to limit infections (e.g., antibiotics, vaccinations, and sanitation strategies) and the incidence of autoimmune and allergic conditions (45). During the COVID19 pandemic, the worldwide increase of sanitation strategies and the use of numerous types of disinfectants and household products raise concerns around their implications on immune health, especially with the concomitant emergence of allergic and autoimmune conditions (386). Could hygiene measures and specifically the use of disinfectants affect the microbial and immunological modulation of autoimmunity? Although studies investigating the immunopathogenic potential of disinfectants are limited, here we briefly propose three possible mechanisms of 
TABLE 1 | The positive influence of specific dietary nutrients on SLE.

\begin{tabular}{|c|c|c|c|}
\hline $\begin{array}{l}\text { Dietary } \\
\text { Factors }\end{array}$ & Data on murine studies of SLE & $\begin{array}{l}\text { Human studies that warrant further } \\
\text { investigation }\end{array}$ & Proposed research directions \\
\hline
\end{tabular}

VE - VE supplementation to NZBWF1 diminished anti-dsDNA autoantibodies and counteracted oxidative stress (121).

VD

- Low levels of VD promoted memory B cells in $A c t 1^{-1-}$ mouse (162).

- VD deficiency increased type $1 \mathrm{IFN}$ gene expression in MRL/pr mice (336).

- Treatment of MRL/pr mice with VDR agonist paricalcitol mitigated • lupus nephritis via modulating the NF-kB/NLRP3/caspase-1/L$1 \beta / \mathrm{LL}-18$ axis and suppressing NF-KB nuclear translocation (337).

VA

- Supplementation of all-trans-retinoic acid (tRA) to murine lupus models drove disease-stage dependent effects on the development of lupus nephritis. During the active disease stages in MRL/pr and pristane-induced lupus mouse models, tRA oral dosing showed beneficial effects on renal inflammation (172-174).
- Supplementation of VE with prednisolone reduced anti-dsDNA antibodies independently of its antioxidant activity (335).

- Supplementation of VE with Nigella sativa improved oxidative and nitrosative biomarkers and SLE disease activity favoring antioxidant therapy in SLE (124).

- A significant negative association between serum VD and memory B cells was confirmed in a cohort of SLE patients (162).

SLE patients with high anti-dsDNA autoantibodies (338) or renal involvement (339) are at higher risk for developing hypovitaminosis D; and low levels of VD are correlated with high disease activity (161).

- Polymorphism in VDR genes has been reported in SLE patients (170).

Hypovitaminosis A has been detected preceding the clinical diagnosis of SLE (169).
- Delineating the effects of VE independently of other components of treatment regimes.

- Exploring the possible diseasestage-dependent or tissue-specific outcomes of VE supplementation.

- Investigating whether VD deficiency is a cause or a sequelae to autoimmune progression.

- Reforming genetic association data linking certain genetic susceptibilities and possibilities of VD deficiency for better personalized therapeutic approaches.

- Establishing the desired doses for prophylactic and/or therapeutic

supplementation of VD for SLE patients.

- Testing the potential efficacy and safety of VD supplementation on SLE-associated inflammatory and hemostatic markers in long-term studies.

- Investigating whether VA deficiency is a driving factor for SLE progression.

- Genome-wide association studies to establish whether polymorphisms in VA receptors are causally associated with SLE development.

- Determining the desired doses of prophylactic and/or therapeutic supplementation of VA.

- Testing the safety and efficacy of VA supplementation in SLE patients with different disease manifestations.

Se $\quad$ Se supplementation improved the survival in NZB/NZW F1 mice * (194).

- SE treatment attenuated SLE-associated splenomegaly in B6.Sle1b mice (195).

- SE supplementation in B6.Sle1b mice significantly reduced total • and germinal center B cell numbers, and anti-dsDNA and antiSmRNP autoantibodies (195).

$\omega-3 \quad \cdot \quad \omega-3$ enriched diets dramatically reduced lupus progression,

PUFA mitigating glomerulonephritis and improving survival in different mouse models of SLE (258-261).

- $\omega-3$ diminished anti-dsDNA antibodies $(258,261)$, and circulating • immune complexes and their renal deposition (258).

- $\omega-3$ potentiated the effects of antioxidant enzymes, enhancing the ability of renal cells to eliminate harmful free radicals (259, 261).

- $\quad \omega-3$ reduced the expression of renal pro-inflammatory cytokines including IFN $\gamma$, IL-12, TNF $\alpha$ (259, 261), and renal profibrotic molecules such as TGF $\beta$ and fibronectin-1 (261).
Meta-analysis of genome-wide association studies predicted high Se levels to associate with a decreased risk for SLE (193).

Circulatory Se levels are lower in patients with SLE compared to age- and sexmatched healthy controls (216).

- Fish oil (the marine source of $\omega-3$ ) together with a low-fat diet significantly modified SLE activity (247).

A population-based study suggested that a higher dietary intake of $\omega-3$ fatty acids and lower $\omega-6$ : $\omega-3$ ratios were positively associated with patient-reported favorable outcomes of SLE activity index (340).
- Exploring the potential therapeutic effect of Se supplementation for SLE patients in large-scale studies.

- Elucidating the underlying mechanisms of the potential protective role of Se on the risk for SLE.

- Conducting longer-term trials with larger patient sample sizes to establish the long-term outcomes of $\omega-3$ PUFA supplementation on the SLE activity index.

- Determining the therapeutic efficacy and safety of $\omega-3$ PUFA as part of the therapeutic regimes that include other immunosuppressive agents. how disinfectants could modulate immunity and contribute to autoimmune conditions such as SLE. These include their effects on (1) microbiota diversity, (2) immune cell phenotype and fate, and (3) epigenetic modifications.
Hygiene can disrupt microbiota diversity (387-389), and a positive correlation has been found between microbiota dysbiosis and the increase of autoimmune conditions such as IBD (390392) and SLE (393-397). This concern is escalating due to the 
current COVID-19 pandemic that witnessed a dramatic increase in hygiene practices including the use of detergents and disinfectants (398-400). In fact, these control measures may have long-term consequences on the human microbiome (401, 402). Importantly, a recent report suggests that a disturbed gut microbiota might lead to more severe inflammation in COVID19 , where they found positive correlations between microbial dysbiosis and disease severity as well as inflammatory mediators in COVID-19 patients (403).

The use of disinfectants is well established to alter microbiota diversity and microbial load. Chlorine, which is widely used as a water disinfectant, produces byproducts called trihalomethanes (THMs) that are intestinally absorbed and known to perturb the gut microbiota leading to the elevated relative abundance of Bacteroidetes and a dose-dependent decrease in the ratio of Firmicutes to Bacteroidetes (404). Similarly, a reduced Firmicutes/Bacteroidetes ratio is also evident in different autoimmune diseases $(405,406)$ including SLE (407). The active chemicals in commercial disinfectants and hand sanitizers (e.g., Triclosan, 5-chloro-2-(2,4-dichloro phenoxy) phenyl) could have a profound impact on the gut microbiome (408, $409)$, reducing microbiota diversity $(410,411)$ and increasing the abundance of Lachnospiraceae (412). As mentioned earlier, there is a strong correlation between disrupted microbial communities and systemic autoimmune disease pathogenesis. For instance, in MRL/lpr mice, reduced Lactobacillaceae and increased Lachnospiraceae are associated with lupus onset and progression (413). Thus, COVID-19 related hygiene practices, such as the overuse of disinfectants, could indirectly contribute to autoimmunity through inducing microbiota dysbiosis.

Secondly, the use of disinfectants could also tone the function and fate of immune cells and subsequently shape the outcome of autoimmune disease. We have shown that quaternary ammonium compounds (QACs) in widely used antiseptics and surface disinfectants (414) can impair innate immune cell functions (415). QACs increase the production of proinflammatory cytokines from murine macrophages in vitro and paradoxically impair their phagocytic potential (415). Since prompt macrophage responses are crucial for efferocytosis (phagocytosis of dying cells in an inflammatory milieu) as well as effective clearance of autoantigens, these disinfectants could contribute to autoimmunity via impairing macrophages responses $(416,417)$. Using $\mathrm{MRL} / \mathrm{lpr}$ mice, we found that ambient exposure to QACs hindered the migration of bone marrow-derived neutrophils towards inflammatory stimuli and decreased their infiltration into the lymph nodes. In parallel, QACs upregulated splenic neutrophil expression of checkpoint protein programmed death-ligand 1 (PD-L1). Moreover, QAC exposure dampened the activation of splenic $\mathrm{T}$ cells and increased apoptosis of effector $\mathrm{T}$-cell populations, thereby mitigating SLE-associated lymphadenopathy in this mouse model (418). Furthermore, while the phenotype of reduced splenomegaly and lymphadenopathy is an indication of protection against a mouse model of SLE, our findings also indicate that even ambient exposure to QACs could alter neutrophil and T-cell phenotypes, functions, and their fate, raising concerns about the immunotoxicity of these chemicals.

Thirdly, disinfectants may reprogram immune cell functions through epigenetic alteration, thus leading to autoimmunity. For instance, long-term exposure to the chlorine byproducts THMs in drinking water results in global DNA hypomethylation as well as c-Jun gene-specific hypomethylation (419). Inhibition of DNA methylation in differentiating Th cells deviates their cytokine responses towards a pro-inflammatory IFN $\gamma^{+}$phenotype (420). In addition, a low DNA methylation level in mature $\mathrm{T}$ cells could result in T-cell autoreactivity associated with idiopathic SLE (421). These findings on disinfectants and epigenetics warrant further investigations to elaborate their roles in breaking immune homeostasis to promote autoimmunity.

Importantly, while authorities worldwide are more interested in mitigating the spread of COVID-19 infection, the long-term consequences of hygiene strategies on immune modulation need to be addressed. The Centers for Disease Control and Prevention (CDC) recommends to the use of the United States Environmental Protection Agency (EPA) list N-approved disinfectants to combat COVID-19 infection; if the disinfectants on the list are not available, then the bleach solution (Chlorine) is recommended. Notably, QAC-based disinfectants are on the top of the EPA list N. Again, the CDC recommendations raise the concern of whether the overuse of these chemicals by the public could pave the way to autoimmunity as the comet tail of the current pandemic. As we have discussed, QACs and chlorine byproducts have the potential to modulate immune cell fate and induce epigenetic modification, respectively, to break self-tolerance, thus leading to autoimmunity.

\section{SUMMARY}

During the recent decades, improved socio-economic levels have led to modernized dietary and hygiene approaches that are concomitant with an increased prevalence of autoimmune conditions. This suggests the strong influence of environmental factors on immune modulation. Throughout this review, we discussed how dietary components and hygiene could have diverse implications on immune health and importantly, their implication on immune tolerance and autoimmunity. This includes both direct and indirect effects on immune cell programming. Direct effects are those on cell signaling, cell metabolism and energy intake, and epigenetic modification; and indirect effects include those modulating antioxidant capacities and gut microbiota. The emergence of the COVID-19 pandemic has greatly impacted our dietary and hygiene behaviors. It is thus important to consider the immunomodulatory capacities of environmental factors especially for patients suffering from both COVID-19 and autoimmune disease. Future studies will unravel much-needed mechanistic insights on the immune modulation induced by diet and hygiene and lead to more effective management strategies for autoimmune diseases during emerging threats such as COVID-19. 


\section{AUTHOR CONTRIBUTIONS}

Both authors listed have made a substantial, direct, and intellectual contribution to the work.

\section{REFERENCES}

1. Williams A. Basic Concepts in Immunology. In: Immunology: Mucosal and Body Surface Defences Chichester. UK: John Wiley \& Sons, Ltd (2011). p. 1-19.

2. Schett G, Neurath MF. Resolution of Chronic Inflammatory Disease: Universal and Tissue-Specific Concepts. Nat Commun (2018) 9(1):1-8. doi: 10.1038/s41467-018-05800-6

3. Viney ME, Riley EM, Buchanan KL. Optimal Immune Responses: Immunocompetence Revisited. Trends Ecol Evol (2005) 20(12):665-9. doi: 10.1016/j.tree.2005.10.003

4. Chaplin DD. Overview of the Immune Response. J Allergy Clin Immunol (2010) 125(2):S3-S23. doi: 10.1016/j.jaci.2009.12.980

5. Janeway CAJr. The Immune System Evolved to Discriminate Infectious Nonself From Noninfectious Self. Immunol Today (1992) 13(1):11-6. doi: 10.1016/0167-5699(92)90198-G

6. Ganz T. Epithelia: Not Just Physical Barriers. Proc Natl Acad Sci (2002) 99 (6):3357-8. doi: 10.1073/pnas.072073199

7. Hiemstra PS. The Role of Epithelial $\beta$-Defensins and Cathelicidins in Host Defense of the Lung. Exp Lung Res (2007) 33(10):537-42. doi: 10.1080/ 01902140701756687

8. Koenderman L, Buurman W, Daha MR. The Innate Immune Response. Immunol Lett (2014) 162(2):95-102. doi: 10.1016/j.imlet.2014.10.010

9. CA Janeway ed. Approaching the Asymptote? Evolution and Revolution in Immunology. In: Cold Spring Harbor Symposia on Quantitative Biology. Cold Spring Harbor Laboratory Press. doi: 10.1101/SQB.1989.054.01.003

10. Cao X. Self-Regulation and Cross-Regulation of Pattern-Recognition Receptor Signalling in Health and Disease. Nat Rev Immunol (2016) 16 (1):35. doi: 10.1038/nri.2015.8

11. Medzhitov R, Janeway CAJr. Innate Immunity: Impact on the Adaptive Immune Response. Curr Opin Immunol (1997) 9(1):4-9. doi: 10.1016/ S0952-7915(97)80152-5

12. Steinman RM, Hemmi H. Dendritic Cells: Translating Innate to Adaptive Immunity. In: B Pulendran and R Ahmed, editors. From Innate Immunity to Immunological Memory. Berlin, Heidelberg: Springer Berlin Heidelberg (2006). p. 17-58.

13. Pozzi L-AM, Maciaszek JW, Rock KL. Both Dendritic Cells and Macrophages Can Stimulate Naive CD8 T Cells In Vivo to Proliferate, Develop Effector Function, and Differentiate Into Memory Cells. J Immunol (2005) 175(4):2071-81. doi: 10.4049/jimmunol.175.4.2071

14. Bernhard CA, Ried C, Kochanek S, Brocker T. CD169+ Macrophages Are Sufficient for Priming of CTLs With Specificities Left Out by Cross-Priming Dendritic Cells. Proc Natl Acad Sci (2015) 112(17):5461-6. doi: 10.1073/ pnas. 1423356112

15. Kolaczkowska E, Kubes P. Neutrophil Recruitment and Function in Health and Inflammation. Nat Rev Immunol (2013) 13(3):159-75. doi: 10.1038/nri3399

16. Hoebe K, Janssen E, Beutler B. The Interface Between Innate and Adaptive Immunity. Nat Immunol (2004) 5(10):971-4. doi: 10.1038/ni1004-971

17. Baumgartner CK, Malherbe LP. Antigen-Driven T-Cell Repertoire Selection During Adaptive Immune Responses. Immunol Cell Biol (2011) 89(1):54-9. doi: $10.1038 /$ icb.2010.117

18. McHeyzer-Williams M, McLean M, Lalor P, Nossal G. Antigen-Driven B Cell Differentiation In Vivo. J Exp Med (1993) 178(1):295-307. doi: 10.1084/ jem.178.1.295

19. Kapsenberg ML. Dendritic-Cell Control of Pathogen-Driven T-Cell Polarization. Nat Rev Immunol (2003) 3(12):984-93. doi: 10.1038/nri1246

20. Weintraub BC, Goodnow CC. Immune Responses: Costimulatory Receptors Have Their Say. Curr Biol (1998) 8(16):R575-R7. doi: 10.1016/S0960-9822 (07)00365-X

21. Cantrell D. Signaling in Lymphocyte Activation. Cold Spring Harb Perspect Biol (2015) 7(6):a018788. doi: 10.1101/cshperspect.a018788

\section{FUNDING}

Preparation of this manuscript was supported by the NIH/ NIAMS under award number R01-AR073240

22. Janeway CAJr., Travers P, Walport M, Shlomchik MJ. Self-Tolerance and Its Loss. Immunobiology: The Immune System in Health and Disease. 5th Edition. New York: Garland Science (2001).

23. Van Parijs L, Abbas AK. Homeostasis and Self-Tolerance in the Immune System: Turning Lymphocytes Off. Science (1998) 280(5361):243-8. doi $10.1126 /$ science. 280.5361 .243

24. Wang L, Wang FS, Gershwin ME. Human Autoimmune Diseases: A Comprehensive Update. J Internal Med (2015) 278(4):369-95. doi 10.1111/joim. 12395

25. Perl A. Pathogenesis and Spectrum of Autoimmunity. Autoimmunity (2004) 102:1-8. doi: 10.1385/1-59259-805-6:001

26. GH Ring and FG Lakkis eds. Breakdown of Self-Tolerance and the Pathogenesis of Autoimmunity. Semin Nephrol (1999) 19:25-33. doi: 10.1055/s-2008-1040823

27. Miller JF, Flavell RA. T-Cell Tolerance and Autoimmunity in Transgenic Models of Central and Peripheral Tolerance. Curr Opin Immunol (1994) 6 (6):892-9. doi: 10.1016/0952-7915(94)90010-8

28. Shao W-H, Cohen PL. Disturbances of Apoptotic Cell Clearance in Systemic Lupus Erythematosus. Arthritis Res Ther (2011) 13(1):1-7. doi: 10.1186/ $\operatorname{ar} 3206$

29. Elkon K. Apoptosis in SLE-too Little or Too Much? Clin Exp Rheumatol (1994) 12(5):553-9.

30. Stojan G, Petri M. Epidemiology of Systemic Lupus Erythematosus: An Update Curr Opin Rheumatol (2018) 30(2):144. doi: 10.1097/BOR.0000000000000480

31. Costenbader KH, Gay S, Alarcón-Riquelme ME, Iaccarino L, Doria A. Genes, Epigenetic Regulation and Environmental Factors: Which is the Most Relevant in Developing Autoimmune Diseases? Autoimmun Rev (2012) 11(8):604-9. doi: 10.1016/j.autrev.2011.10.022

32. Gutierrez-Roelens I, Lauwerys BR. Genetic Susceptibility to Autoimmune Disorders: Clues From Gene Association and Gene Expression Studies. Curr Mol Med (2008) 8(6):551-61. doi: 10.2174/156652408785747906

33. Heward J, Gough SC. Genetic Susceptibility to the Development of Autoimmune Disease. Clin Sci (1997) 93(6):479-91. doi: 10.1042/cs0930479

34. Inshaw JR, Cutler AJ, Burren OS, Stefana MI, Todd JA. Approaches and Advances in the Genetic Causes of Autoimmune Disease and Their Implications. Nat Immunol (2018) 19(7):674-84. doi: 10.1038/s41590-018$0129-8$

35. Gutierrez-Arcelus M, Rich SS, Raychaudhuri S. Autoimmune DiseasesConnecting Risk Alleles With Molecular Traits of the Immune System. Nat Rev Genet (2016) 17(3):160. doi: 10.1038/nrg.2015.33

36. Ceccarelli F, Agmon-Levin N, Perricone C. Genetic Factors of Autoimmune Diseases. Hindawi (2016). doi: 10.1155/2016/3476023

37. Becker KG. The Common Genetic Hypothesis of Autoimmune/ Inflammatory Disease. Curr Opin Allergy Clin Immunol (2001) 1(5):399405. doi: 10.1097/00130832-200110000-00004

38. Miller FW, Alfredsson L, Costenbader KH, Kamen DL, Nelson LM, Norris JM, et al. Epidemiology of Environmental Exposures and Human Autoimmune Diseases: Findings From a National Institute of Environmental Health Sciences Expert Panel Workshop. J Autoimmun (2012) 39(4):259-71. doi: 10.1016/j.jaut.2012.05.002

39. Tesini BL, Kanagaiah P, Wang J, Hahn M, Halliley JL, Chaves FA, et al. Broad Hemagglutinin-Specific Memory B Cell Expansion by Seasonal Influenza Virus Infection Reflects Early-Life Imprinting and Adaptation to the Infecting Virus. J Virol (2019) 93(8):e00169-19. doi: 10.1128/JVI.00169-19

40. McKeen S, Young W, Mullaney J, Fraser K, McNabb WC, Roy NC. Infant Complementary Feeding of Prebiotics for the Microbiome and Immunity. Nutrients (2019) 11(2):364. doi: 10.3390/nu11020364

41. MacGillivray DM, Kollmann TR. The Role of Environmental Factors in Modulating Immune Responses in Early Life. Front Immunol (2014) 5:434. doi: 10.3389/fimmu.2014.00434 
42. Janeway CAJr., Travers P, Walport M, Shlomchik MJ. Immunological Memory. Immunobiology: The Immune System in Health and Disease. 5th Edition. New York: Garland Science (2001).

43. Lerner A, Jeremias P, Matthias T. The World Incidence and Prevalence of Autoimmune Diseases Is Increasing. Int J Celiac Dis (2015) 3(4):151-5. doi: 10.12691/ijcd-3-4-8

44. Bach J-F. The Hygiene Hypothesis in Autoimmunity: The Role of Pathogens and Commensals. Nat Rev Immunol (2018) 18(2):105. doi: 10.1038/ nri.2017.111

45. Okada H, Kuhn C, Feillet H, Bach JF. The 'Hygiene Hypothesis' for Autoimmune and Allergic Diseases: An Update. Clin Exp Immunol (2010) 160(1):1-9. doi: 10.1111/j.1365-2249.2010.04139.x

46. Frew JW. The Hygiene Hypothesis, Old Friends, and New Genes. Front Immunol (2019) 10:388(388). doi: 10.3389/fimmu.2019.00388

47. Manzel A, Muller DN, Hafler DA, Erdman SE, Linker RA, Kleinewietfeld M. Role of "Western Diet" in Inflammatory Autoimmune Diseases. Curr Allergy Asthma Rep (2014) 14(1):1-8. doi: 10.1007/s11882-013-0404-6

48. Leech B, McEwen B, Owusu Sekyere E. Diet, Digestive Health, and Autoimmunity: The Foundations to an Autoimmune Disease Food Pyramid-Part 1. Altern Complement Ther (2020) 26(3):112-8. doi: 10.1089/act.2020.29278.ble

49. Leech B, McEwen B, Sekyere EO. Diet, Digestive Health, and Autoimmunity: The Foundations to an Autoimmune Disease Food Pyramid-Part 2. Altern Complement Ther (2020) 26(4):158-67. doi: 10.1089/act.2020.29287.ble

50. Gianfrancesco M, Hyrich KL, Al-Adely S, Carmona L, Danila MI, Gossec L, et al. Characteristics Associated With Hospitalisation for COVID-19 in People With Rheumatic Disease: Data From the COVID-19 Global Rheumatology Alliance Physician-Reported Registry. Ann Rheum Dis (2020) 79(7):859-66. doi: 10.1136/annrheumdis-2020-217871

51. Bastard P, Gervais A, Le Voyer T, Rosain J, Philippot Q, Manry J, et al. Autoantibodies Neutralizing Type I IFNs Are Present in 4\% of Uninfected Individuals Over 70 Years Old and Account for 20\% of COVID-19 Deaths. Sci Immunol (2021) 6(62):eabl4340. doi: 10.1126/sciimmunol.abl4340

52. Bastard P, Rosen LB, Zhang Q, Michailidis E, Hoffmann H-H, Zhang Y, et al. Autoantibodies Against Type I IFNs in Patients With Life-Threatening COVID-19. Science (2020) 370(6515):eabd4585. doi: 10.1126/science. abd 4585

53. Gupta S, Nakabo S, Chu J, Hasni S, Kaplan MJ. Association Between AntiInterferon-Alpha Autoantibodies and COVID-19 in Systemic Lupus Erythematosus. Medrxiv (2020). doi: 10.1101/2020.10.29.20222000

54. Wang EY, Mao T, Klein J, Dai Y, Huck JD, Jaycox JR, et al. Diverse Functional Autoantibodies in Patients With COVID-19. Nature (2021) 595:283-8. doi: 10.1038/s41586-021-03631-y

55. Talotta R, Robertson E. Autoimmunity as the Comet Tail of COVID-19 Pandemic. World J Clin Cases (2020) 8(17):3621. doi: 10.12998/ wjcc.v8.i17.3621

56. Cañas CA. The Triggering of Post-COVID-19 Autoimmunity Phenomena Could be Associated With Both Transient Immunosuppression and an Inappropriate Form of Immune Reconstitution in Susceptible Individuals. Med Hypotheses (2020) 145:110345. doi: 10.1016/j.mehy.2020.110345

57. Caso F, Costa L, Ruscitti P, Navarini L, Del Puente A, Giacomelli R, et al. Could Sars-Coronavirus-2 Trigger Autoimmune and/or Autoinflammatory Mechanisms in Genetically Predisposed Subjects? Autoimmun Rev (2020) 19 (5):102524. doi: 10.1016/j.autrev.2020.102524

58. Bennett G, Young E, Butler I, Coe S. The Impact of Lockdown During the COVID-19 Outbreak on Dietary Habits in Various Population Groups: A Scoping Review. Front Nutr (2021) 8:53. doi: 10.3389/fnut.2021.626432

59. Irelli EC, Orlando B, Cocchi E, Morano A, Fattapposta F, Di Piero V, et al. The Potential Impact of Enhanced Hygienic Measures During the COVID19 Outbreak on Hospital-Acquired Infections: A Pragmatic Study in Neurological Units. J Neurol Sci (2020) 418:117111. doi: 10.1016/ j.jns.2020.117111

60. Dalton C, Corbett S, Katelaris A. Pre-Emptive Low Cost Social Distancing and Enhanced Hygiene Implemented Before Local COVID-19 Transmission Could Decrease the Number and Severity of Cases. Med J Aust (2020) 212 (10):1. doi: $10.2139 /$ ssrn. 3549276

61. Volynets V, Louis S, Pretz D, Lang L, Ostaff MJ, Wehkamp J, et al. Intestinal Barrier Function and the Gut Microbiome Are Differentially Affected in
Mice Fed a Western-Style Diet or Drinking Water Supplemented With Fructose. J Nutr (2017) 147(5):770-80. doi: 10.3945/jn.116.242859

62. Raman KG, Sappington PL, Yang R, Levy RM, Prince JM, Liu S, et al. The Role of RAGE in the Pathogenesis of Intestinal Barrier Dysfunction After Hemorrhagic Shock. Am J Physiol Gastrointest Liver Physiol (2006) 291(4): G556-G65. doi: 10.1152/ajpgi.00055.2006

63. Maggini S, Beveridge S, Sorbara P, Senatore G. Feeding the Immune System: The Role of Micronutrients in Restoring Resistance to Infections. CAB Rev: Perspect Agric Vet Sci Nutr Nat Resour (2008) 3(098):1-21. doi: 10.1079/ PAVSNNR20083098

64. Clairmont A, Tessmann D, Stock A, Nicolai S, Stahi W, Sies H. Induction of Gap Junctional Intercellular Communication by Vitamin D in Human Skin Fibroblasts Is Dependent on the Nuclear Vitamin D Receptor. Carcinogenesis (1996) 17(6):1389-91. doi: 10.1093/carcin/17.6.1389

65. Wang T-T, Nestel FP, Bourdeau V, Nagai Y, Wang Q, Liao J, et al. Cutting Edge: 1, 25-Dihydroxyvitamin D3 Is a Direct Inducer of Antimicrobial Peptide Gene Expression. J Immunol (2004) 173(5):2909-12. doi: 10.4049/ jimmunol.173.5.2909

66. Li K, Huang T, Zheng J, Wu K, Li D. Effect of Marine-Derived N-3 Polyunsaturated Fatty Acids on C-Reactive Protein, Interleukin 6 and Tumor Necrosis Factor $\alpha$ : A Meta-Analysis. PloS One (2014) 9(2):e88103. doi: 10.1371 /journal.pone. 0088103

67. Reichel H, Koeffler HP, Tobler A, Norman AW. 1 Alpha, 25Dihydroxyvitamin D3 Inhibits Gamma-Interferon Synthesis by Normal Human Peripheral Blood Lymphocytes. Proc Natl Acad Sci (1987) 84 (10):3385-9. doi: 10.1073/pnas.84.10.3385

68. Zhang Y, Leung DY, Richers BN, Liu Y, Remigio LK, Riches DW, et al. Vitamin D Inhibits Monocyte/Macrophage Proinflammatory Cytokine Production by Targeting MAPK Phosphatase-1. J Immunol (2012) 188 (5):2127-35. doi: 10.4049/jimmunol.1102412

69. Benson MJ, Pino-Lagos K, Rosemblatt M, Noelle RJ. All-Trans Retinoic Acid Mediates Enhanced T Reg Cell Growth, Differentiation, and Gut Homing in the Face of High Levels of Co-Stimulation. J Exp Med (2007) 204(8):176574. doi: $10.1084 /$ jem. 20070719

70. Kinoshita M, Kayama H, Kusu T, Yamaguchi T, Kunisawa J, Kiyono H, et al. Dietary Folic Acid Promotes Survival of Foxp3+ Regulatory T Cells in the Colon. J Immunol (2012) 189(6):2869-78. doi: 10.4049/jimmunol.1200420

71. Luo T, Ji W-j, Yuan F, Guo Z-z, Li Y-x, Dong Y, et al. Th17/Treg Imbalance Induced by Dietary Salt Variation Indicates Inflammation of Target Organs in Humans. Sci Rep (2016) 6(1):1-12. doi: 10.1038/srep26767

72. Matsui T, Takahashi R, Nakao Y, Koizumi T, Katakami Y, Mihara K, et al. 1, 25-Dihydroxyvitamin D3-Regulated Expression of Genes Involved in Human T-Lymphocyte Proliferation and Differentiation. Cancer Res (1986) 46(11):5827-31.

73. Estruch R. Anti-Inflammatory Effects of the Mediterranean Diet: The Experience of the PREDIMED Study. Proc Nutr Soc (2010) 69(3):333-40. doi: $10.1017 /$ S0029665110001539

74. Conforti F, Sosa S, Marrelli M, Menichini F, Statti GA, Uzunov D, et al. In Vivo Anti-Inflammatory and In Vitro Antioxidant Activities of Mediterranean Dietary Plants. J Ethnopharmacol (2008) 116(1):144-51. doi: 10.1016/j.jep.2007.11.015

75. Pocovi-Gerardino G, Correa-Rodríguez M, Callejas-Rubio J-L, RíosFernández R, Martín-Amada M, Cruz-Caparros M-G, et al. Beneficial Effect of Mediterranean Diet on Disease Activity and Cardiovascular Risk in Systemic Lupus Erythematosus Patients: A Cross-Sectional Study. Rheumatology (2021) 60(1):160-9. doi: 10.1093/rheumatology/keaa210

76. Khan H, Sureda A, Belwal T, Cetinkaya S, Süntar I, Tejada S, et al. Polyphenols in the Treatment of Autoimmune Diseases. Autoimmun Rev (2019) 18(7):647-57. doi: 10.1016/j.autrev.2019.05.001

77. Ginwala R, Bhavsar R, Chigbu DGI, Jain P, Khan ZK. Potential Role of Flavonoids in Treating Chronic Inflammatory Diseases With a Special Focus on the Anti-Inflammatory Activity of Apigenin. Antioxidants (2019) 8(2):35. doi: 10.3390/antiox8020035

78. Krasuska A, Gorzel M. Alleviation of Erythematous Changes in Systemic Lupus Erythematosus (Cutaneous Lupus Erythematosus) With the Use of Flavonoids-Case Study. Arch Physiother Global Res (2020) 24(2):7-16. doi 10.15442/apgr.24.2.1

79. Hosseinzade A, Sadeghi O, Naghdipour Biregani A, Soukhtehzari S, Brandt GS, Esmaillzadeh A. Immunomodulatory Effects of Flavonoids: Possible 
Induction of T CD4+ Regulatory Cells Through Suppression of mTOR Pathway Signaling Activity. Front Immunol (2019) 10:51. doi: 10.3389/ fimmu.2019.00051

80. Hong Y-H, Wang T-C, Huang C-J, Cheng W-Y, Lin B-F. Soy Isoflavones Supplementation Alleviates Disease Severity in Autoimmune-Prone MRLLpr/Lpr Mice. Lupus (2008) 17(9):814-21. doi: 10.1177/ 0961203308091287

81. Jensen SN, Cady NM, Shahi SK, Peterson SR, Gupta A, Gibson-Corley KN, et al. Isoflavone Diet Ameliorates Experimental Autoimmune Encephalomyelitis Through Modulation of Gut Bacteria Depleted in Patients With Multiple Sclerosis. Sci Adv (2021) 7(28):eabd4595. doi: 10.1126/sciadv.abd4595

82. Aday S, Aday MS. Impact of COVID-19 on the Food Supply Chain. Food Qual Saf (2020) 4(4):167-80. doi: 10.1093/fqsafe/fyaa024

83. Kim H, Rebholz CM, Hegde S, LaFiura C, Raghavan M, Lloyd JF, et al. PlantBased Diets, Pescatarian Diets and COVID-19 Severity: A Population-Based Case-Control Study in Six Countries. BMJ Nutr Prev Health (2021) 4 (1):257-66. doi: 10.1136/bmjnph-2021-000272

84. Zhang M, Swarts SG, Yin L, Liu C, Tian Y, Cao Y, et al. Antioxidant Properties of Quercetin. Adv Exp Med Biol (2011) 701:283-9. doi: 10.1007/ 978-1-4419-7756-4_38

85. Lesjak M, Beara I, Simin N, Pintać D, Majkić T, Bekvalac K, et al. Antioxidant and Anti-Inflammatory Activities of Quercetin and Its Derivatives. J Funct Foods (2018) 40:68-75. doi: 10.1016/j.jff.2017.10.047

86. Gu Y-Y, Zhang M, Cen H, Wu Y-F, Lu Z, Lu F, et al. Quercetin as a Potential Treatment for COVID-19-Induced Acute Kidney Injury: Based on Network Pharmacology and Molecular Docking Study. PloS One (2021) 16(1): e0245209. doi: 10.1371/journal.pone.0245209

87. Hirsch JS, Ng JH, Ross DW, Sharma P, Shah HH, Barnett RL, et al. Acute Kidney Injury in Patients Hospitalized With COVID-19. Kidney Int (2020) 98(1):209-18. doi: 10.1016/j.kint.2020.05.006

88. Nadim MK, Forni LG, Mehta RL, Connor MJ, Liu KD, Ostermann M, et al. COVID-19-Associated Acute Kidney Injury: Consensus Report of the 25th Acute Disease Quality Initiative (ADQI) Workgroup. Nat Rev Nephrol (2020) 16(12):747-64. doi: 10.1038/s41581-020-00356-5

89. Javadi F, Ahmadzadeh A, Eghtesadi S, Aryaeian N, Zabihiyeganeh M, Rahimi Foroushani A, et al. The Effect of Quercetin on Inflammatory Factors and Clinical Symptoms in Women With Rheumatoid Arthritis: A Double-Blind, Randomized Controlled Trial. J Am Coll Nutr (2017) 36(1):915. doi: 10.1080/07315724.2016.1140093

90. Guazelli CF, Staurengo-Ferrari L, Zarpelon AC, Pinho-Ribeiro FA, RuizMiyazawa KW, Vicentini FT, et al. Quercetin Attenuates Zymosan-Induced Arthritis in Mice. Biomed Pharmacother (2018) 102:175-84. doi: 10.1016/ j.biopha.2018.03.057

91. Yuan K, Zhu Q, Lu Q, Jiang H, Zhu M, Li X, et al. Quercetin Alleviates Rheumatoid Arthritis by Inhibiting Neutrophil Inflammatory Activities. J Nutr Biochem (2020) 84:108454. doi: 10.1016/j.jnutbio.2020.108454

92. Yang Y, Zhang X, Xu M, Wu X, Zhao F, Zhao C. Quercetin Attenuates Collagen-Induced Arthritis by Restoration of Th17/Treg Balance and Activation of Heme Oxygenase 1-Mediated Anti-Inflammatory Effect. Int Immunopharmacol (2018) 54:153-62. doi: 10.1016/j.intimp.2017.11.013

93. Comalada M, Camuesco D, Sierra S, Ballester I, Xaus J, Gálvez J, et al. In Vivo Quercitrin Anti-Inflammatory Effect Involves Release of Quercetin, Which Inhibits Inflammation Through Down-Regulation of the NF-kb Pathway. Eur J Immunol (2005) 35(2):584-92. doi: 10.1002/eji.200425778

94. Dong Y, Lei J, Zhang B. Dietary Quercetin Alleviated DSS-Induced Colitis in Mice Through Several Possible Pathways by Transcriptome Analysis. Curr Pharm Biotechnol (2020) 21(15):1666-73. doi: 10.2174/ 1389201021666200711152726

95. Li W, Li H, Zhang M, Wang M, Zhong Y, Wu H, et al. Quercitrin Ameliorates the Development of Systemic Lupus Erythematosus-Like Disease in a Chronic Graft-Versus-Host Murine Model. Am J Physiol Renal Physiol (2016) 311(1):F217-F26. doi: 10.1152/ajprenal.00249.2015

96. Gombart AF, Pierre A, Maggini S. A Review of Micronutrients and the Immune System-Working in Harmony to Reduce the Risk of Infection. Nutrients (2020) 12(1):236. doi: 10.3390/nu12010236

97. Bendich A. Antioxidant Vitamins and Their Functions in Immune Responses. Antioxidant Nutrients and Immune Functions. In: Advances in
Experimental Medicine and Biology. Boston, MA: Springer (1990) 262:3555. doi: 10.1007/978-1-4613-0553-8_4

98. Ramani S, Pathak A, Dalal V, Paul A, Biswas S. Oxidative Stress in Autoimmune Diseases: An Under Dealt Malice. Curr Protein Pept Sci (2020) 21(6):611-21. doi: 10.2174/1389203721666200214111816

99. Kumagai S, Jikimoto T, Saegusa J. Pathological Roles of Oxidative Stress in Autoimmune Diseases. Rinsho Byori (2003) 51(2):126-32.

100. Colucci R, Dragoni F, Moretti S. Oxidative Stress and Immune System in Vitiligo and Thyroid Diseases. Oxid Med Cell Longev (2015) 2015, 632927. doi: $10.1155 / 2015 / 631927$

101. Su L-J, Zhang J-H, Gomez H, Murugan R, Hong X, Xu D, et al. Reactive Oxygen Species-Induced Lipid Peroxidation in Apoptosis, Autophagy, and Ferroptosis. Oxid Med Cell Longev (2019) 2019:5080843.. doi: 10.1155/2019/ 5080843

102. Roshchupkin D, Murina M. Free-Radical and Cyclooxygenase-Catalyzed Lipid Peroxidation in Membranes of Blood Cells Under UV Irradiation. Membr Cell Biol (1998) 12(2):279-86.

103. Matsushita M, Freigang S, Schneider C, Conrad M, Bornkamm GW, Kopf M. T Cell Lipid Peroxidation Induces Ferroptosis and Prevents Immunity to Infection. J Exp Med (2015) 212(4):555-68. doi: 10.1084/jem.20140857

104. Leitinger N. The Role of Phospholipid Oxidation Products in Inflammatory and Autoimmune Diseases. Lipids Health Dis (2008) 49:325-50. doi: 10.1007/978-1-4020-8830-8_12

105. Kurien BT, Scofield RH. Lipid Peroxidation in Systemic Lupus Erythematosus. Indian J Exp Biol (2006) 44(5):349-56.

106. Wang G, König R, Ansari G, Khan MF. Lipid Peroxidation-Derived Aldehyde-Protein Adducts Contribute to Trichloroethene-Mediated Autoimmunity via Activation of CD4+ T Cells. Free Radic Biol Med (2008) 44(7):1475-82. doi: 10.1016/j.freeradbiomed.2008.01.012

107. Griffiths HR. ROS as Signalling Molecules in T Cells-Evidence for Abnormal Redox Signalling in the Autoimmune Disease, Rheumatoid Arthritis. Redox Rep (2005) 10(6):273-80. doi: 10.1179/135100005X83680

108. Glennon-Alty L, Hackett AP, Chapman EA, Wright HL. Neutrophils and Redox Stress in the Pathogenesis of Autoimmune Disease. Free Radic Biol Med (2018) 125:25-35. doi: 10.1016/j.freeradbiomed.2018.03.049

109. Derouiche S. Oxidative Stress Associated With SARS-Cov-2 (COVID-19) Increases the Severity of the Lung Disease-a Systematic Review. J Infect Dis Epidemiol (2020) 6(121). doi: 10.23937/2474-3658/1510121

110. Forcados GE, Muhammad A, Oladipo OO, Makama S, Meseko CA. Metabolic Implications of Oxidative Stress and Inflammatory Process in SARS-CoV-2 Pathogenesis: Therapeutic Potential of Natural Antioxidants. Front Cell Infect Microbiol (2021) 11:457. doi: 10.3389/fcimb.2021.654813

111. Cecchini R, Cecchini AL. SARS-CoV-2 Infection Pathogenesis is Related to Oxidative Stress as a Response to Aggression. Med Hypotheses (2020) 143:110102. doi: 10.1016/j.mehy.2020.110102

112. Jialal I, Devaraj S, Kaul N. The Effect of $\alpha$-Tocopherol on Monocyte Proatherogenic Activity. J Nutr (2001) 131(2):389S-94S. doi: 10.1093/jn/ 131.2.389S

113. Ayres S, Mihan R. Is Vitamin E Involved in the Autoimmune Mechanism? Cutis (1978) 21(3):321-5.

114. Szodoray P, Horvath IF, Papp G, Barath S, Gyimesi E, Csathy L, et al. The Immunoregulatory Role of Vitamins A, D and E in Patients With Primary Sjögren's Syndrome. Rheumatology (2010) 49(2):211-7. doi: 10.1093/ rheumatology/kep374

115. Mauro A, Orsi L, Mortara P, Costa P, Schiffer D. Cerebellar Syndrome in Adult Celiac Disease With Vitamin E Deficiency. Acta Neurol Scand (1991) 84(2):167-70. doi: 10.1111/j.1600-0404.1991.tb04927.x

116. Sikora SK, Spady D, Prosser C, El-Matary W. Trace Elements and Vitamins at Diagnosis in Pediatric-Onset Inflammatory Bowel Disease. Clin Pediatr (2011) 50(6):488-92. doi: 10.1177/0009922810397041

117. Xiong RB, Li Q, Wan WR, Guo JQ, Luo BD, Gan L. Effects and Mechanisms of Vitamin A and Vitamin E on the Levels of Serum Leptin and Other Related Cytokines in Rats With Rheumatoid Arthritis. Exp Ther Med (2014) 8(2):499-504. doi: 10.3892/etm.2014.1777

118. Alorainy M. Effect of Allopurinol and Vitamin E on Rat Model of Rheumatoid Arthritis. Int J Health Sci (2008) 2(1):59.

119. Ayres S, Mihan R. Lupus Erythematosus and Vitamin E: An Effective and Nontoxic Therapy. Cutis (1979) 23(1):49-52, 4. 
120. Chou C. Alternative Therapies: What Role do They Have in the Management of Lupus? Lupus (2010) 19(12):1425-9. doi: 10.1177/0961203310379872

121. Hsieh C-C, Lin B-F. The Effects of Vitamin E Supplementation on Autoimmune-Prone New Zealand Blackx New Zealand White F1 Mice Fed an Oxidised Oil Diet. Br J Nutr (2005) 93(5):655-62. doi: 10.1079/ BJN20051413

122. Avalos I, Chung C, Oeser A, Milne G, Morrow J, Gebretsadik T, et al. Oxidative Stress in Systemic Lupus Erythematosus: Relationship to Disease Activity and Symptoms. Lupus (2007) 16(3):195-200. doi: 10.1177/ 0961203306075802

123. Shah D, Kiran R, Wanchu A, Bhatnagar A. Oxidative Stress in Systemic Lupus Erythematosus: Relationship to Th1 Cytokine and Disease Activity. Immunol Lett (2010) 129(1):7-12. doi: 10.1016/j.imlet.2010.01.005

124. Shahba A, Esheba NE, Fooda A-A, El-Dardiry S, Wagih A, el-Deeb O. Effect of Nigella Sativa and Vitamin E on Some Oxidative/Nitrosative Biomarkers in Systemic Lupus Erythematosus Patients. Life Sci J (2015) 12:157-62.

125. Penna G, Adorini L. 1 $\alpha$, 25-Dihydroxyvitamin D3 Inhibits Differentiation, Maturation, Activation, and Survival of Dendritic Cells Leading to Impaired Alloreactive T Cell Activation. J Immunol (2000) 164(5):2405-11. doi: 10.4049/jimmunol.164.5.2405

126. D’Ambrosio D, Cippitelli M, Cocciolo MG, Mazzeo D, Di Lucia P, Lang R, et al. Inhibition of IL-12 Production by 1, 25-Dihydroxyvitamin D3. Involvement of NF-kappaB Downregulation in Transcriptional Repression of the P40 Gene. J Clin Invest (1998) 101(1):252-62. doi: 10.1172/JCI1050

127. Adorini L, Penna G. Dendritic Cell Tolerogenicity: A Key Mechanism in Immunomodulation by Vitamin D Receptor Agonists. Hum Immunol (2009) 70(5):345-52. doi: 10.1016/j.humimm.2009.01.016

128. Ferreira GB, Vanherwegen A-S, Eelen G, Gutiérrez ACF, Van Lommel L, Marchal K, et al. Vitamin D3 Induces Tolerance in Human Dendritic Cells by Activation of Intracellular Metabolic Pathways. Cell Rep (2015) 10 (5):711-25. doi: 10.1016/j.celrep.2015.01.013

129. Strober W. Vitamin A Rewrites the ABCs of Oral Tolerance. Mucosal Immunol (2008) 1(2):92-5. doi: 10.1038/mi.2007.22

130. Geissmann F, Revy P, Brousse N, Lepelletier Y, Folli C, Durandy A, et al. Retinoids Regulate Survival and Antigen Presentation by Immature Dendritic Cells. J Exp Med (2003) 198(4):623-34. doi: 10.1084/jem.20030390

131. Lackey DE, Ashley SL, Davis AL, Hoag KA. Retinoic Acid Decreases Adherence of Murine Myeloid Dendritic Cells and Increases Production of Matrix Metalloproteinase-9. J Nutr (2008) 138(8):1512-9. doi: 10.1093/jn/ 138.8.1512

132. Liao X, Reihl AM, Luo XM. Breakdown of Immune Tolerance in Systemic Lupus Erythematosus by Dendritic Cells. J Immunol Res (2016) 2016:6269157. doi: 10.1155/2016/6269157

133. Barragan M, Good M, Kolls JK. Regulation of Dendritic Cell Function by Vitamin D. Nutrients (2015) 7(9):8127-51. doi: 10.3390/nu7095383

134. Cassani B, Villablanca EJ, De Calisto J, Wang S, Mora JR. Vitamin A and Immune Regulation: Role of Retinoic Acid in Gut-Associated Dendritic Cell Education, Immune Protection and Tolerance. Mol Aspects Med (2012) 33 (1):63-76. doi: 10.1016/j.mam.2011.11.001

135. S Manicassamy and B Pulendran eds. Retinoic Acid-Dependent Regulation of Immune Responses by Dendritic Cells and Macrophages. Semin Immunol (2009) 21(1):22-7. doi: 10.1016/j.smim.2008.07.007

136. van Etten E, Mathieu C. Immunoregulation by 1, 25-Dihydroxyvitamin D3: Basic Concepts. J Steroid Biochem Mol Biol (2005) 97(1-2):93-101. doi: 10.1016/j.jsbmb.2005.06.002

137. Lemire JM, Archer DC, Beck L, Spiegelberg HL. Immunosuppressive Actions of 1, 25-Dihydroxyvitamin D3: Preferential Inhibition of Th1 Functions. J Nutr (1995) 125(suppl_6):1704S-8S. doi: 10.1016/0960-0760(95)00106-A

138. Cippitelli M, Santoni A. Vitamin D3: A Transcriptional Modulator of the Interferon- $\gamma$ Gene. Eur J Immunol (1998) 28(10):3017-30. doi: 10.1002/ (SICI)1521-4141(199810)28:10<3017::AID-IMMU3017>3.0.CO;2-6

139. Stephensen CB, Rasooly R, Jiang X, Ceddia MA, Weaver CT, Chandraratna RA, et al. Vitamin A Enhances In Vitro Th2 Development via Retinoid X Receptor Pathway. J Immunol (2002) 168(9):4495-503. doi: 10.4049/ jimmunol.168.9.4495

140. Spilianakis CG, Lee GR, Flavell RA. Twisting the Th1/Th2 Immune Response via the Retinoid X Receptor: Lessons From a Genetic Approach. Eur J Immunol (2005) 35(12):3400-4. doi: 10.1002/eji.200535588
141. Iwata M, Eshima Y, Kagechika H. Retinoic Acids Exert Direct Effects on T Cells to Suppress Th1 Development and Enhance Th2 Development via Retinoic Acid Receptors. Int Immunol (2003) 15(8):1017-25. doi: 10.1093/ intimm/dxg101

142. Kang SW, Kim SH, Lee N, Lee W-W, Hwang K-A, Shin MS, et al. 1,25Dihyroxyvitamin D3 Promotes FOXP3 Expression via Binding to Vitamin D Response Elements in Its Conserved Noncoding Sequence Region. J Immunol (Baltimore Md: 1950) (2012) 188(11):5276-82. doi: 10.4049/ jimmunol.1101211

143. Tian A, Ma H, Cao X, Zhang R, Wang X, Wu B. Vitamin D Improves Cognitive Function and Modulates T H 17/T Reg Cell Balance After Hepatectomy in Mice. Inflammation (2015) 38(2):500-9. doi: 10.1007/ s10753-014-9956-4

144. Kim CH. Regulation of FoxP 3+ Regulatory T Cells and Th17 Cells by Retinoids. Clin Dev Immunol (2008) 2008:416910. doi: 10.1155/2008/416910

145. Z Chen, A Laurence and JJ O'Shea eds. Signal Transduction Pathways and Transcriptional Regulation in the Control of Th17 Differentiation. Semin Immunol (2007) 19(6):400-8. doi: 10.1016/j.smim.2007.10.015

146. Lu L, Ma J, Li Z, Lan Q, Chen M, Liu Y, et al. All-Trans Retinoic Acid Promotes TGF- $\beta$-Induced Tregs via Histone Modification But Not DNA Demethylation on Foxp3 Gene Locus. PloS One (2011) 6(9):e24590. doi: 10.1371/journal.pone.0024590

147. Skapenko A, Leipe J, Lipsky PE, Schulze-Koops H. The Role of the T Cell in Autoimmune Inflammation. Arthritis Res Ther (2005) 7(2):1-11. doi: $10.1186 /$ ar1703

148. Dejaco C, Duftner C, Grubeck-Loebenstein B, Schirmer M. Imbalance of Regulatory T Cells in Human Autoimmune Diseases. Immunology (2006) 117(3):289-300. doi: 10.1111/j.1365-2567.2005.02317.x

149. A Ascherio and K Munger eds. Epidemiology of Multiple Sclerosis: From Risk Factors to Prevention. Semin Neurol (2016) 36(2):103-14. doi: 10.1055/ s-0036-1579693

150. Beretich B, Beretich T. Explaining Multiple Sclerosis Prevalence by Ultraviolet Exposure: A Geospatial Analysis. Mult Scler J (2009) 15 (8):891-8. doi: 10.1177/1352458509105579

151. Ponsonby A-L, McMichael A, van der Mei I. Ultraviolet Radiation and Autoimmune Disease: Insights From Epidemiological Research. Toxicology (2002) 181:71-8. doi: 10.1016/S0300-483X(02)00257-3

152. Ban Y, Taniyama M, Ban Y. Vitamin D Receptor Gene Polymorphism is Associated With Graves' Disease in the Japanese Population. J Clin Endocrinol Metab (2000) 85(12):4639-43. doi: 10.1210/jcem.85.12.7038

153. Ban Y, Taniyama M, Ban Y. Vitamin D Receptor Gene Polymorphisms in Hashimoto's Thyroiditis. Thyroid (2001) 11(6):607-8. doi: 10.1089/ 105072501750302967

154. Boraska V, Škrabić V, Zeggini E, Groves CJ, Buljubašić M, Peruzović M, et al. Family-Based Analysis of Vitamin D Receptor Gene Polymorphisms and Type 1 Diabetes in the Population of South Croatia. J Hum Genet (2008) 53 (3):210-4. doi: 10.1007/s10038-007-0234-2

155. Fukazawa T, Yabe I, Kikuchi S, Sasaki H, Hamada T, Miyasaka K, et al. Association of Vitamin D Receptor Gene Polymorphism With Multiple Sclerosis in Japanese. J Neurol Sci (1999) 166(1):47-52. doi: 10.1016/S0022510X(99)00112-4

156. Maalej A, Petit-Teixeira E, Michou L, Rebai A, Cornélis F, Ayadi H. Association Study of VDR Gene With Rheumatoid Arthritis in the French Population. Genes Immun (2005) 6(8):707-11. doi: 10.1038/sj.gene.6364260

157. Sakulpipatsin W, Verasertniyom O, Nantiruj K, Totemchokchyakarn K, Lertsrisatit P, Janwityanujit S. Vitamin D Receptor Gene BsmI Polymorphisms in Thai Patients With Systemic Lupus Erythematosus. Arthritis Res Ther (2006) 8(2):1-4. doi: 10.1186/ar1910

158. Wright TB, Shults J, Leonard MB, Zemel BS, Burnham JM. Hypovitaminosis D is Associated With Greater Body Mass Index and Disease Activity in Pediatric Systemic Lupus Erythematosus. J Pediatr (2009) 155(2):260-5. doi: 10.1016/j.jpeds.2009.02.033

159. Borba V, Vieira J, Kasamatsu T, Radominski S, Sato E, Lazaretti-Castro M. Vitamin D Deficiency in Patients With Active Systemic Lupus Erythematosus. Osteoporos Int (2009) 20(3):427-33. doi: 10.1007/s00198-008-0676-1

160. Kamen DL, Cooper GS, Bouali H, Shaftman SR, Hollis BW, Gilkeson GS. Vitamin D Deficiency in Systemic Lupus Erythematosus. Autoimmun Rev (2006) 5(2):114-7. doi: 10.1016/j.autrev.2005.05.009 
161. Yap KS-Y, Northcott M, Hoi AB, Morand EF, Nikpour M. Association of Low Vitamin D With High Disease Activity in an Australian Systemic Lupus Erythematosus Cohort. Lupus Sci Med (2015) 2(1):e000064. doi: 10.1136/ lupus-2014-000064

162. Yamamoto EA, Nguyen JK, Liu J, Keller E, Campbell N, Zhang C-J, et al. Low Levels of Vitamin D Promote Memory B Cells in Lupus. Nutrients (2020) 12 (2):291. doi: 10.3390/nu12020291

163. Ritterhouse LL, Crowe SR, Niewold TB, Kamen DL, Macwana SR, Roberts VC, et al. Vitamin D Deficiency Is Associated With an Increased Autoimmune Response in Healthy Individuals and in Patients With Systemic Lupus Erythematosus. Ann Rheum Dis (2011) 70(9):1569-74. doi: 10.1136/ard.2010.148494

164. Dankers W, Colin EM, van Hamburg JP, Lubberts E. Vitamin D in Autoimmunity: Molecular Mechanisms and Therapeutic Potential. Front Immunol (2017) 7:697. doi: 10.3389/fimmu.2016.00697

165. D'Avolio A, Avataneo V, Manca A, Cusato J, De Nicolò A, Lucchini R, et al. 25-Hydroxyvitamin D Concentrations Are Lower in Patients With Positive PCR for SARS-CoV-2. Nutrients (2020) 12(5):1359. doi: 10.3390/ nu12051359

166. Arvinte C, Singh M, Marik PE. Serum Levels of Vitamin C and Vitamin D in a Cohort of Critically Ill COVID-19 Patients of a North American Community Hospital Intensive Care Unit in May 2020: A Pilot Study. Med Drug Discov (2020) 8:100064. doi: 10.1016/j.medidd.2020.100064

167. Annweiler C, Hanotte B, de l'Eprevier CG, Sabatier J-M, Lafaie L, Célarier T. Vitamin D and Survival in COVID-19 Patients: A Quasi-Experimental Study. J Steroid Biochem Mol Biol (2020) 204:105771. doi: 10.1016/ j.jsbmb.2020.105771

168. Filippi M, Preziosa P, Rocca MA. Vitamin A: Yet Another Player in Multiple Sclerosis Pathogenesis? Expert Rev Clin Immunol (2013) 9(2):113-5. doi: 10.1586/eci.12.105

169. Comstock G, Burke A, Hoffman S, Helzlsouer K, Bendich A, Masi A, et al. Serum Concentrations of $\alpha$ Tocopherol, $\beta$ Carotene, and Retinol Preceding the Diagnosis of Rheumatoid Arthritis and Systemic Lupus Erythematosus. Ann Rheum Dis (1997) 56(5):323-5. doi: 10.1136/ ard.56.5.323

170. Azab SF, Ali YF, Farghaly MA, Hamed ME, Allah MA, Emam AA, et al. Vitamin D Receptor Gene BsmI Polymorphisms in Egyptian Children and Adolescents With Systemic Lupus Erythematosus: A Case-Control Study. Medicine (2016) 95(46). doi: 10.1097/MD.0000000000005233

171. Abdelhamid L, Luo XM. Retinoic Acid, Leaky Gut, and Autoimmune Diseases. Nutrients (2018) 10(8):1016. doi: 10.3390/nu10081016

172. Abdelhamid L, Cabana-Puig X, Swartwout B, Lee J, Li S, Sun S, et al. Retinoic Acid Exerts Disease Stage-Dependent Effects on Pristane-Induced Lupus. Front Immunol (2020) 11:408(408). doi: 10.3389/fimmu.2020.00408

173. Liao X, Ren J, Wei C-H, Ross AC, Cecere TE, Jortner BS, et al. Paradoxical Effects of All-Trans-Retinoic Acid on Lupus-Like Disease in the MRL/lpr Mouse Model. PloS One (2015) 10(3):e0118176. doi: 10.1371/ journal.pone.0118176

174. Handono K, Firdausi SN, Pratama MZ, Endharti AT, Kalim H. Vitamin A Improve Th17 and Treg Regulation in Systemic Lupus Erythematosus. Clin Rheumatol (2016) 35(3):631-8. doi: 10.1007/s10067-016-3197-x

175. Sarohan AR, Akelma H, Arac E, Aslan O. Retinol Depletion in Severe COVID-19. medRxiv (2021). doi: 10.1101/2021.01.30.21250844

176. Sarohan AR. COVID-19: Endogenous Retinoic Acid Theory and Retinoic Acid Depletion Syndrome. Med Hypotheses (2020) 144:110250. doi: 10.1016/ j.mehy.2020.110250

177. Midha IK, Kumar N, Kumar A, Madan T. Mega Doses of Retinol: A Possible Immunomodulation in Covid-19 Illness in Resource-Limited Settings. Rev Med Virol (2021) 31(5):1-14. doi: 10.1002/rmv.2204

178. Zidenberg-Cherr S, Keen CL. Essential Trace Elements in Antioxidant Processes. In: Trace Elements, Micronutrients, and Free Radicals. Springer (1991). p. 107-27. doi: 10.1007/978-1-4612-0419-0_5

179. Wołonciej M, Milewska E, Roszkowska-Jakimiec W. Trace Elements as an Activator of Antioxidant Enzymes. Postepy Hig Med Dosw (Online) (2016) 70:1483-98. doi: 10.5604/17322693.1229074

180. Huskisson E, Maggini S, Ruf M. The Role of Vitamins and Minerals in Energy Metabolism and Well-Being. J Int Med Res (2007) 35(3):277-89. doi: $10.1177 / 147323000703500301$
181. Kudrin A. Trace Elements in Regulation of NF-אb Activity. J Trace Elem Med Biol (2000) 14(3):129-42. doi: 10.1016/S0946-672X(00)80001-2

182. Haase H, Maret W. Intracellular Zinc Fluctuations Modulate Protein Tyrosine Phosphatase Activity in Insulin/Insulin-Like Growth Factor-1 Signaling. Exp Cell Res (2003) 291(2):289-98. doi: 10.1016/S0014-4827(03) 00406-3

183. Pan J, Huang X, Li Y, Li M, Yao N, Zhou Z, et al. Zinc Protects Against Cadmium-Induced Toxicity by Regulating Oxidative Stress, Ions Homeostasis and Protein Synthesis. Chemosphere (2017) 188:265-73. doi: 10.1016/j.chemosphere.2017.08.106

184. Kimball SR, Chen S-J, Risica R, Jefferson LS, Leure-duPree AE. Effects of Zinc Deficiency on Protein Synthesis and Expression of Specific mRNAs in Rat Liver. Metabolism (1995) 44(1):126-33. doi: 10.1016/0026-0495(95)90299-6

185. Baraboĭ V, Shestakova E. Selenium: The Biological Role and Antioxidant Activity. Ukr Biokhim Zh (2004) 76(1):23-32.

186. Rotruck JT, Pope AL, Ganther HE, Swanson A, Hafeman DG, Hoekstra W. Selenium: Biochemical Role as a Component of Glutathione Peroxidase. Science (1973) 179(4073):588-90. doi: 10.1126/science.179.4073.588

187. Wise D, Tomasso J, Gatlin IIID, Bai S, Blazer VS. Effects of Dietary Selenium and Vitamin E on Red Blood Cell Peroxidation, Glutathione Peroxidase Activity, and Macrophage Superoxide Anion Production in Channel Catfish. J Aquat Anim Health (1993) 5(3):177-82. doi: 10.1577/1548-8667(1993) 005<0177:EODSAV >2.3.CO;2

188. Pang Z, Chen Y, Zhou M, Wan J. Effect of Polysaccharide Krestin on Glutathione Peroxidase Gene Expression in Mouse Peritoneal Macrophages. Br J Biomed Sci (2000) 57(2):130.

189. Loeb GA, Skelton DC, Coates TD, Forman HJ. Role of Selenium-Dependent Glutathione Peroxidase in Antioxidant Defenses in Rat Alveolar Macrophages. Exp Lung Res (1988) 14(sup1):921-36. doi: 10.3109/ 01902148809064184

190. Parnham MJ, Winkelmann J, Leyck S. Macrophage, Lymphocyte and Chronic Inflammatory Responses in Selenium Deficient Rodents. Association With Decreased Glutathione Peroxidase Activity. Int $J$ Immunopharmacol (1983) 5(5):455-61. doi: 10.1016/0192-0561(83)90022-x

191. Duntas L. Selenium and Inflammation: Underlying Anti-Inflammatory Mechanisms. Horm Metab Res (2009) 41(06):443-7. doi: 10.1055/s-00291220724

192. Stazi A, Trinti B. Selenium Deficiency in Celiac Disease: Risk of Autoimmune Thyroid Diseases. Minerva Med (2008) 99(6):643-53.

193. Ye D, Sun X, Guo Y, Shao K, Qian Y, Huang H, et al. Genetically Determined Selenium Concentrations and Risk for Autoimmune Diseases. Nutrition (2021) 91:111391. doi: 10.1016/j.nut.2021.111391

194. O’Dell JR, McGivern JP, Kay H, Klassen LW. Improved Survival in Murine Lupus as the Result of Selenium Supplementation. Clin Exp Immunol (1988) 73(2):322.

195. Soni C, Sinha I, Fasnacht MJ, Olsen NJ, Rahman ZS, Sinha R. Selenium Supplementation Suppresses Immunological and Serological Features of Lupus in B6. Sle1b Mice. Autoimmunity (2019) 52(2):57-68. doi: 10.1080/ 08916934.2019 .1603297

196. Moghaddam A, Heller RA, Sun Q, Seelig J, Cherkezov A, Seibert L, et al. Selenium Deficiency is Associated With Mortality Risk From COVID-19. Nutrients (2020) 12(7):2098. doi: 10.3390/nu12072098

197. Maares M, Haase H. Zinc and Immunity: An Essential Interrelation. Arch Biochem Biophys (2016) 611:58-65. doi: 10.1016/j.abb.2016.03.022

198. Siebenlist U, Franzoso G, Brown K. Structure, Regulation and Function of NF-Kappab. Annu Rev Cell Biol (1994) 10(1):405-55. doi: 10.1146/ annurev.cb.10.110194.002201

199. Haase H, Rink L. Signal Transduction in Monocytes: The Role of Zinc Ions. Biometals (2007) 20(3):579-85. doi: 10.1007/s10534-006-9029-8

200. Stafford SL, Bokil NJ, Achard ME, Kapetanovic R, Schembri MA, McEWAN AG, et al. Metal Ions in Macrophage Antimicrobial Pathways: Emerging Roles for Zinc and Copper. Biosci Rep (2013) 33(4):e00049. doi: 10.1042/ BSR20130014

201. Wirth J, Fraker P, Kierszenbaum F. Zinc Requirement for Macrophage Function: Effect of Zinc Deficiency on Uptake and Killing of a Protozoan Parasite. Immunology (1989) 68(1):114.

202. Xin L, Yang X, Cai G, Fan D, Xia Q, Liu L, et al. Serum Levels of Copper and Zinc in Patients With Rheumatoid Arthritis: A Meta-Analysis. Biol Trace Elem Res (2015) 168(1):1-10. doi: 10.1007/s12011-015-0325-4 
203. George MM, Vignesh KS, Figueroa JAL, Caruso JA, Deepe GS. Zinc Induces Dendritic Cell Tolerogenic Phenotype and Skews Regulatory T Cell-Th17 Balance. J Immunol (2016) 197(5):1864-76. doi: 10.4049/jimmunol.1600410

204. Kaltenberg J, Plum LM, Ober-Blöbaum JL, Hönscheid A, Rink L, Haase H. Zinc Signals Promote IL-2-Dependent Proliferation of T Cells. Eur J Immunol (2010) 40(5):1496-503. doi: 10.1002/eji.200939574

205. Tanaka Y, Shiozawa S, Morimoto I, Fujita T. Role of Zinc in Interleukin 2 (IL-2)-Mediated T-Cell Activation. Scand J Immunol (1990) 31(5):547-52. doi: 10.1111/j.1365-3083.1990.tb02805.x

206. Bao B, Prasad AS, Beck FW, Bao GW, Singh T, Ali S, et al. Intracellular Free Zinc Up-Regulates IFN- $\gamma$ and T-Bet Essential for Th1 Differentiation in ConA Stimulated HUT-78 Cells. Biochem Biophys Res Commun (2011) 407 (4):703-7. doi: 10.1016/j.bbrc.2011.03.084

207. Prasad AS. Effects of Zinc Deficiency on Th1 and Th2 Cytokine Shifts. J Infect Dis (2000) 182(Supplement_1):S62-S8. doi: 10.1086/315916

208. Maywald M, Rink L. Zinc Supplementation Induces CD4+ CD25+ Foxp3+ Antigen-Specific Regulatory T Cells and Suppresses IFN- $\gamma$ Production by Upregulation of Foxp3 and KLF-10 and Downregulation of IRF-1. Eur J Nutr (2017) 56(5):1859-69. doi: 10.1007/s00394-016-1228-7

209. Kitabayashi C, Fukada T, Kanamoto M, Ohashi W, Hojyo S, Atsumi T, et al. Zinc Suppresses Th17 Development via Inhibition of STAT3 Activation. Int Immunol (2010) 22(5):375-86. doi: 10.1093/intimm/dxq017

210. Lee H, Kim B, Choi YH, Hwang Y, Kim DH, Cho S, et al. Inhibition of Interleukin-1 $\beta$-Mediated Interleukin-1 Receptor-Associated Kinase 4 Phosphorylation by Zinc Leads to Repression of Memory T Helper Type 17 Response in Humans. Immunology (2015) 146(4):645-56. doi: 10.1111/ imm. 12536

211. Rosenkranz E, Maywald M, Hilgers R-D, Brieger A, Clarner T, Kipp M, et al. Induction of Regulatory $\mathrm{T}$ Cells in Th1-/Th17-Driven Experimental Autoimmune Encephalomyelitis by Zinc Administration. J Nutr Biochem (2016) 29:116-23. doi: 10.1016/j.jnutbio.2015.11.010

212. Stoye D, Schubert C, Goihl A, Guttek K, Reinhold A, Brocke S, et al. Zinc Aspartate Suppresses T Cell Activation In Vitro and Relapsing Experimental Autoimmune Encephalomyelitis in SJL/J Mice. Biometals (2012) 25(3):52939. doi: 10.1007/s10534-012-9532-Z

213. Sanna A, Firinu D, Zavattari P, Valera P. Zinc Status and Autoimmunity: A Systematic Review and Meta-Analysis. Nutrients (2018) 10(1):68. doi: 10.3390/nu10010068

214. Pawlitzki M, Uebelhör J, Sweeney-Reed CM, Stephanik H, Hoffmann J, Lux A, et al. Lower Serum Zinc Levels in Patients With Multiple Sclerosis Compared to Healthy Controls. Nutrients (2018) 10(8):967. doi: 10.3390/ nu10080967

215. Yilmaz A, Sari RA, Gundogdu M, Kose N, Dag E. Trace Elements and Some Extracellular Antioxidant Proteins Levels in Serum of Patients With Systemic Lupus Erythematosus. Clin Rheumatol (2005) 24(4):331-5. doi: 10.1007/ s10067-004-1028-y

216. Sahebari M, Abrishami-Moghaddam M, Moezzi A, Ghayour-Mobarhan M, Mirfeizi Z, Esmaily H, et al. Association Between Serum Trace Element Concentrations and the Disease Activity of Systemic Lupus Erythematosus. Lupus (2014) 23(8):793-801. doi: 10.1177/0961203314530792

217. Jothimani D, Kailasam E, Danielraj S, Nallathambi B, Ramachandran H, Sekar P, et al. COVID-19: Poor Outcomes in Patients With Zinc Deficiency. Int J Infect Dis (2020) 100:343-9. doi: 10.1016/j.ijid.2020.09.014

218. Samad N, Dutta S, Sodunke TE, Fairuz A, Sapkota A, Miftah ZF, et al. FatSoluble Vitamins and the Current Global Pandemic of COVID-19: EvidenceBased Efficacy From Literature Review. J Inflamm Res (2021) 14:2091. doi: 10.2147/JIR.S307333

219. Richardson DP, Lovegrove JA. Nutritional Status of Micronutrients as a Possible and Modifiable Risk Factor for COVID-19: A UK Perspective. $\mathrm{Br} \mathrm{J}$ Nutr (2021) 125(6):678-84. doi: 10.1017/S000711452000330X

220. Carr AC. Micronutrient Status of COVID-19 Patients: A Critical Consideration. Crit Care (2020) 24(1):1-2. doi: 10.1186/s13054-020-03085-0

221. San-Cristobal R, Navas-Carretero S, Martínez-González MÁ, Ordovas JM, Martínez JA. Contribution of Macronutrients to Obesity: Implications for Precision Nutrition. Nat Rev Endocrinol (2020) 16(6):305-20. doi: 10.1038/ s41574-020-0346-8

222. Yang J, Hu J, Zhu C. Obesity Aggravates COVID-19: A Systematic Review and Meta-Analysis. J Med Virol (2021) 93(1):257-61. doi: 10.1002/jmv.26237
223. Popkin BM, Du S, Green WD, Beck MA, Algaith T, Herbst CH, et al. Individuals With Obesity and COVID-19: A Global Perspective on the Epidemiology and Biological Relationships. Obes Rev (2020) 21(11):e13128. doi: $10.1111 /$ obr.13128

224. Goyal P, Ringel JB, Rajan M, Choi JJ, Pinheiro LC, Li HA, et al. Obesity and COVID-19 in New York City: A Retrospective Cohort Study. Ann Internal Med (2020) 173(10):855-8. doi: 10.7326/M20-2730

225. Nakeshbandi M, Maini R, Daniel P, Rosengarten S, Parmar P, Wilson C, et al. The Impact of Obesity on COVID-19 Complications: A Retrospective Cohort Study. Int J Obes (2020) 44(9):1832-7. doi: 10.1038/s41366-0200648-x

226. Eliasson A-C. Carbohydrates in Food. Boca Raton, FL: CRC press (2006) 159.

227. Hachimura S, Totsuka M, Hosono A. Immunomodulation by Food: Impact on Gut Immunity and Immune Cell Function. Biosci Biotechnol Biochem (2018) 82(4):584-99. doi: 10.1080/09168451.2018.1433017

228. Wu H-J, Wu E. The Role of Gut Microbiota in Immune Homeostasis and Autoimmunity. Gut Microbes (2012) 3(1):4-14. doi: 10.4161/gmic.19320

229. Shokryazdan P, Jahromi MF, Navidshad B, Liang JB. Effects of Prebiotics on Immune System and Cytokine Expression. Med Microbiol Immunol (2017) 206(1):1-9. doi: 10.1007/s00430-016-0481-y

230. Chen J, Seviour R. Medicinal Importance of Fungal $\beta-(1 \rightarrow 3),(1 \rightarrow 6)$ Glucans. Mycol Res (2007) 111(6):635-52. doi: 10.1016/j.mycres.2007.02.011

231. Borchers AT, Krishnamurthy A, Keen CL, Meyers FJ, Gershwin ME. The Immunobiology of Mushrooms. Exp Biol Med (2008) 233(3):259-76. doi: 10.3181/0708-MR-227

232. Ganeshan K, Chawla A. Metabolic Regulation of Immune Responses. Annu Rev Immunol (2014) 32:609-34. doi: 10.1146/annurev-immunol-032713120236

233. Saltiel AR, Olefsky JM. Inflammatory Mechanisms Linking Obesity and Metabolic Disease. J Clin Invest (2017) 127(1):1-4. doi: 10.1172/JCI92035

234. Hotamisligil GS. Inflammation and Metabolic Disorders. Nature (2006) 444 (7121):860-7. doi: 10.1038/nature05485

235. Zhang D, Jin W, Wu R, Li J, Park S-A, Tu E, et al. High Glucose Intake Exacerbates Autoimmunity Through Reactive-Oxygen-Species-Mediated TGF- $\beta$ Cytokine Activation. Immunity (2019) 51(4):671-81.e5. doi: 10.1016/j.immuni.2019.08.001

236. Klack K, Bonfa E, Borba Neto EF. Diet and Nutritional Aspects in Systemic Lupus Erythematosus. Rev Bras Reumatol (2012) 52(3):395-408. doi: 10.1590/S0482-50042012000300009

237. Berer K, Martínez I, Walker A, Kunkel B, Schmitt-Kopplin P, Walter J, et al. Dietary Non-Fermentable Fiber Prevents Autoimmune Neurological Disease by Changing Gut Metabolic and Immune Status. Sci Rep (2018) 8(1):1-12. doi: 10.1038/s41598-018-28839-3

238. Dash R, Mitra S, Ali MC, Oktaviani DF, Hannan M, Choi SM, et al. Phytosterols: Targeting Neuroinflammation in Neurodegeneration. Curr Pharm Des (2021) 27(3):383-401. doi: 10.2174/1381612826666200628022812

239. Valerio M, Liu H-b, Heffner R, Zivadinov R, Ramanathan M, WeinstockGuttman B, et al. Phytosterols Ameliorate Clinical Manifestations and Inflammation in Experimental Autoimmune Encephalomyelitis. Inflamm Res (2011) 60(5):457-65. doi: 10.1007/s00011-010-0288-z

240. Endres S, Meydani SN, Ghorbani R, Schindler R, Dinarello CA. Dietary Supplementation With N-3 Fatty Acids Suppresses Interleukin-2 Production and Mononuclear Cell Proliferation. J Leukoc Biol (1993) 54(6):599-603. doi: 10.1002/jlb.54.6.599

241. Las Heras V, Clooney AG, Ryan FJ, Cabrera-Rubio R, Casey PG, Hueston $\mathrm{CM}$, et al. Short-Term Consumption of a High-Fat Diet Increases Host Susceptibility to Listeria Monocytogenes Infection. Microbiome (2019) 7 (1):1-12. doi: 10.1186/s40168-019-0621-x

242. Goldberg EL, Molony RD, Kudo E, Sidorov S, Kong Y, Dixit VD, et al. Ketogenic Diet Activates Protective $\gamma \delta$ T Cell Responses Against Influenza Virus Infection. Sci Immunol (2019) 4(41):eaav2026. doi: 10.1126/sciimmunol.aav2026

243. Fernandes G. Dietary Lipids and Risk of Autoimmune Disease. Clin Immunol Immunopathol (1994) 72(2):193-7. doi: 10.1006/clin.1994.1129

244. Morrow W, Ohashi Y, Hall J, Pribnow J, Hirose S, Shirai T, et al. Dietary Fat and Immune Function. I. Antibody Responses, Lymphocyte and Accessory Cell Function in (NZB X NZW) F1 Mice. J Immunol (1985) 135(6):3857-63.

245. Hanna Kazazian N, Wang Y, Roussel-Queval A, Marcadet L, Chasson L, Laprie C, et al. Lupus Autoimmunity and Metabolic Parameters Are 
Exacerbated Upon High Fat Diet-Induced Obesity Due to TLR7 Signaling. Front Immunol (2019) 10:2015. doi: 10.3389/fimmu.2019.02015

246. Zhang X, Meng J, Shi X, Ali H, Hellmers L, Mathew N, et al. Lupus Pathogenesis and Autoimmunity Are Exacerbated by High Fat DietInduced Obesity in Mice. Am Assoc Immnol (2020) 10:2015. doi: 10.3389/ fimmu.2019.02015.

247. Walton A, Snaith M, Locniskar M, Cumberland A, Morrow W, Isenberg D. Dietary Fish Oil and the Severity of Symptoms in Patients With Systemic Lupus Erythematosus. Ann Rheum Dis (1991) 50(7):463-6. doi: 10.1136/ ard.50.7.463

248. Swidsinski A, Dörffel Y, Loening-Baucke V, Gille C, Göktas Ö, Reißhauer A, et al. Reduced Mass and Diversity of the Colonic Microbiome in Patients With Multiple Sclerosis and Their Improvement With Ketogenic Diet. Front Microbiol (2017) 8:1141. doi: 10.3389/fmicb.2017.01141

249. Tóth C, Clemens Z. Type 1 Diabetes Mellitus Successfully Managed With the Paleolithic Ketogenic Diet. Int J Case Rep Images (2014) 5(10):699-703. doi: 10.5348/ijcri-2014124-CR-10435

250. Gangitano E, Tozzi R, Gandini O, Watanabe M, Basciani S, Mariani S, et al. Ketogenic Diet as a Preventive and Supportive Care for COVID-19 Patients. Nutrients (2021) 13(3):1004. doi: 10.3390/nu13031004

251. Sukkar SG, Cogorno L, Pisciotta L, Pasta A, Vena A, Gradaschi R, et al. Clinical Efficacy of Eucaloric Ketogenic Nutrition in the COVID-19 Cytokine Storm: A Retrospective Analysis of Mortality and Intensive Care Unit Admission. Nutrition (2021) 89:111236. doi: 10.1016/j.nut.2021.111236

252. Azary S, Schreiner T, Graves J, Waldman A, Belman A, Guttman BW, et al. Contribution of Dietary Intake to Relapse Rate in Early Paediatric Multiple Sclerosis. J Neurol Neurosurg Psychiatry (2018) 89(1):28-33. doi: 10.1136/ jnnp-2017-315936

253. McKellar G, Morrison E, McEntegart A, Hampson R, Tierney A, Mackle G, et al. A Pilot Study of a Mediterranean-Type Diet Intervention in Female Patients With Rheumatoid Arthritis Living in Areas of Social Deprivation in Glasgow. Ann Rheum Dis (2007) 66(9):1239-43. doi: 10.1136/ ard.2006.065151

254. MDR Huerta, MM Trujillo-Martín, Í Rúa-Figueroa, L Cuellar-Pompa, R Quirós-López, P Serrano-Aguilar and S Spanish eds. Healthy Lifestyle Habits for Patients With Systemic Lupus Erythematosus: A Systemic Review. Semin Arthritis Rheum (2015) 45(4):463-70. doi: 10.1016/ j.semarthrit.2015.09.003

255. Greene MW, Roberts AP, Frugé AD. Negative Association Between Mediterranean Diet Adherence and COVID-19 Cases and Related Deaths in Spain and 25 OECD Countries: An Ecological Study. Front Nutr (2021) 8:74. doi: $10.3389 /$ fnut.2021.591964

256. Angelidi AM, Kokkinos A, Katechaki E, Ros E, Mantzoros CS. Mediterranean Diet as a Nutritional Approach for COVID-19. Metab Clin $\operatorname{Exp}$ (2021) 114:154407. doi: 10.1016/j.metabol.2020.154407

257. Detopoulou P, Demopoulos CA, Antonopoulou S. Micronutrients, Phytochemicals and Mediterranean Diet: A Potential Protective Role Against COVID-19 Through Modulation of PAF Actions and Metabolism. Nutrients (2021) 13(2):462. doi: 10.3390/nu13020462

258. Alexander NJ, Smythe N, Jokinen M. The Type of Dietary Fat Affects the Severity of Autoimmune Disease in NZB/NZW Mice. Am J Pathol (1987) 127(1):106.

259. Jolly CA, Muthukumar A, Avula CR, Troyer D, Fernandes G. Life Span is Prolonged in Food-Restricted Autoimmune-Prone (NZB $\times$ NZW) F (1) Mice Fed a Diet Enriched With (N-3) Fatty Acids. J Nutr (2001) 131(10):2753-60. doi: $10.1093 / \mathrm{jn} / 131.10 .2753$

260. Chandrasekar B, Fernandes G. Decreased Proinflammatory Cytokines and Increased Antioxidant Enzyme Gene Expression by $\omega-3$ Lipids in Murine Lupus Nephritis. Biochem Biophys Res Commun (1994) 200(2):893-8. doi: 10.1006/bbrc.1994.1534

261. Chandrasekar B, Troyer DA, Venkatraman JT, Fernandes G. Dietary Omega-3 Lipids Delay the Onset and Progression of Autoimmune Lupus Nephritis by Inhibiting Transforming Growth Factor $\beta$ mRNA and Protein Expression. J Autoimmun (1995) 8(3):381-93. doi: 10.1006/jaut.1995.0030

262. Wierenga KA, Strakovsky RS, Benninghoff AD, Rajasinghe LD, Lock AL, Harkema JR, et al. Requisite Omega-3 HUFA Biomarker Thresholds for Preventing Murine Lupus Flaring. Front Immunol (2020) 11:1796. doi: 10.3389/fimmu.2020.01796
263. Feng C, Keisler D, Fritsche K. Dietary Omega-3 Polyunsaturated Fatty Acids Reduce IFN-Gamma Receptor Expression in Mice. J Interf Cytokine Res (1999) 19(1):41-8. doi: 10.1089/107999099314405

264. Pestka JJ, Vines LL, Bates MA, He K, Langohr I. Comparative Effects of N-3, N-6 and N-9 Unsaturated Fatty Acid-Rich Diet Consumption on Lupus Nephritis, Autoantibody Production and CD4+ T Cell-Related Gene Responses in the Autoimmune NZBWF1 Mouse. PloS One (2014) 9(6): e100255. doi: 10.1371/journal.pone.0100255

265. Charpentier C, Chan R, Salameh E, Mbodji K, Ueno A, Coëffier M, et al. Dietary N-3 PUFA May Attenuate Experimental Colitis. Mediators Inflamm (2018) 2018:8430614. doi: 10.1155/2018/8430614

266. Arnardottir H, Pawelzik S-C, Öhlund Wistbacka U, Artiach G, Hofmann R, Reinholdsson I, et al. Stimulating the Resolution of Inflammation Through Omega-3 Polyunsaturated Fatty Acids in COVID-19: Rationale for the COVID-Omega-F Trial. Front Physiol (2021) 11:1748. doi: 10.3389/ fphys.2020.624657

267. Chang JP-C, Pariante CM, Su K-P. Omega-3 Fatty Acids in the Psychological and Physiological Resilience Against COVID-19. Prostaglandins Leukot Essent Fatty Acids (2020) 161:102177. doi: 10.1016/j.plefa.2020.102177

268. Asher A, Tintle NL, Myers M, Lockshon L, Bacareza H, Harris WS. Blood Omega-3 Fatty Acids and Death From COVID-19: A Pilot Study. Prostaglandins Leukot Essent Fatty Acids (2021) 166:102250. doi: 10.1016/ j.plefa.2021.102250

269. Li P, Yin Y-L, Li D, Kim SW, Wu G. Amino Acids and Immune Function. $B r$ J Nutr (2007) 98(2):237-52. doi: 10.1017/S000711450769936X

270. Zhao J, Zhang X, Liu H, Brown MA, Qiao S. Dietary Protein and Gut Microbiota Composition and Function. Curr Protein Pept Sci (2019) 20 (2):145-54. doi: 10.2174/1389203719666180514145437

271. da Silva Menezes J, de Sousa Mucida D, Cara DC, Alvarez-Leite JI, Russo M, Vaz NM, et al. Stimulation by Food Proteins Plays a Critical Role in the Maturation of the Immune System. Int Immunol (2003) 15(3):447-55. doi: 10.1093/intimm/dxg043

272. Amaral JF, Gomes-Santos AC, Paula-Silva J, Nicoli JR, Vieira LQ, Faria AM, et al. Antigenic Dietary Protein Guides Maturation of the Host Immune System Promoting Resistance to Leishmania Major Infection in C57BL/6 Mice. Immunology (2010) 129(3):455-64. doi: 10.1111/j.1365-2567.2009. 03198.x

273. Paula-Silva J, Santiago AF, Oliveira RP, Rosa MLP, Carvalho CR, Amaral JF, et al. Effect of a Protein-Free Diet in the Development of Food Allergy and Oral Tolerance in BALB/c Mice. Br J Nutr (2015) 113(6):935-43. doi: 10.1017/S0007114515000173

274. Pabst O, Mowat A. Oral Tolerance to Food Protein. Mucosal Immunol (2012) 5(3):232-9. doi: 10.1038/mi.2012.4

275. Amaral J, Foschetti DA, Assis F, Menezes J, Vaz N, Faria A. Immunoglobulin Production is Impaired in Protein-Deprived Mice and Can be Restored by Dietary Protein Supplementation. Braz J Med Biol Res (2006) 39(12):1581-6. doi: 10.1590/S0100-879X2006001200009

276. Deitch EA, Ma W-J, Ma L, Berg RD, Specian RD. Protein Malnutrition Predisposes to Inflammatory-Induced Gut-Origin Septic States. Ann Surg (1990) 211(5):560. doi: 10.1097/00000658-199005000-00006

277. Aycart DF, Acevedo S, Eguiguren-Jimenez L, Andrade JM. Influence of Plant and Animal Proteins on Inflammation Markers Among Adults With Chronic Kidney Disease: A Systematic Review and Meta-Analysis. Nutrients (2021) 13(5):1660. doi: 10.3390/nu13051660

278. Kostovcikova K, Coufal S, Galanova N, Fajstova A, Hudcovic T, Kostovcik $\mathrm{M}$, et al. Diet Rich in Animal Protein Promotes Pro-Inflammatory Macrophage Response and Exacerbates Colitis in Mice. Front Immunol (2019) 10:919. doi: 10.3389/fimmu.2019.00919

279. Fouque D, Aparicio M. Eleven Reasons to Control the Protein Intake of Patients With Chronic Kidney Disease. Nat Clin Pract Nephrol (2007) 3 (7):383-92. doi: 10.1038/ncpneph0524

280. Ko GJ, Obi Y, Tortoricci AR, Kalantar-Zadeh K. Dietary Protein Intake and Chronic Kidney Disease. Curr Opin Clin Nutr Metab Care (2017) 20(1):77. doi: 10.1097/MCO.0000000000000342

281. Milovanov YS, Lysenko LV, Milovanova LY, Dobrosmyslov IA, Milovanov YS, Lysenko L, et al. The Role of Balanced Low-Protein Diet in Inhibition of Progression of Predialysis Chronic Disease of the Kidneys in Systemic Diseases. Ter Arkh (2009) 81(8):52-7. 
282. Fernandes G, Yunis EJ, Good RA. Influence of Protein Restriction on Immune Functions in NZB Mice. J Immunol (1976) 116(3):782-90.

283. Procaccini C, Carbone F, Galgani M, La Rocca C, De Rosa V, Cassano S, et al. Obesity and Susceptibility to Autoimmune Diseases. Expert Rev Clin Immunol (2011) 7(3):287-94. doi: 10.1586/eci.11.18

284. Al Nabhani Z, Dulauroy S, Lécuyer E, Polomack B, Campagne P, Berard M, et al. Excess Calorie Intake Early in Life Increases Susceptibility to Colitis in Adulthood. Nat Metab (2019) 1(11):1101-9. doi: 10.1038/s42255-019-0129-5

285. Baranowska-Bik A, Bik W. The Association of Obesity With Autoimmune Thyroiditis and Thyroid Function-Possible Mechanisms of Bilateral Interaction. Int J Endocrinol (2020) 2020:8894792. doi: 10.1155/2020/ 8894792

286. Kubo C, Johnson BC, Day NK, Good RA. Effects of Calorie Restriction on Immunologic Functions and Development of Autoimmune Disease in NZB Mice. Proc Soc Exp Biol Med (1992) 201(2):192-9. doi: 10.3181/00379727201-43498

287. Ogura M, Ogura H, Ikehara S, Dao ML, Good RA. Decrease by Chronic Energy Intake Restriction of Cellular Proliferation in the Intestinal Epithelium and Lymphoid Organs in Autoimmunity-Prone Mice. Proc Natl Acad Sci (1989) 86(15):5918-22. doi: 10.1073/pnas.86.15.5918

288. Muthukumar AR, Jolly CA, Zaman K, Fernandes G. Calorie Restriction Decreases Proinflammatory Cytokines and Polymeric Ig Receptor Expression in the Submandibular Glands of Autoimmune Prone (NZB $\times$ NZW) F1 Mice. J Clin Immunol (2000) 20(5):354-61. doi: 10.1023/ A:1006620130114

289. Troyer D, Chandrasekar B, Barnes J, Fernandes G. Calorie Restriction Decreases Platelet-Derived Growth Factor (PDGF)-A and Thrombin Receptor mRNA Expression in Autoimmune Murine Lupus Nephritis. Clin Exp Immunol (1997) 108(1):58-62. doi: 10.1046/j.13652249.1997.d01-970.x

290. Mizutani H, Engelman RW, Kinjoh K, Kurata Y, Ikehara S, Matsuzawa Y, et al. Calorie Restriction Prevents the Occlusive Coronary Vascular Disease of Autoimmune (NZW X BXSB) F1 Mice. Proc Natl Acad Sci (1994) 91 (10):4402-6. doi: 10.1073/pnas.91.10.4402

291. Sun D, Krishnan A, Su J, Lawrence R, Zaman K, Fernandes G. Regulation of Immune Function by Calorie Restriction and Cyclophosphamide Treatment in Lupus-Prone NZB/NZW F1 Mice. Cell Immunol (2004) 228(1):54-65. doi: 10.1016/j.cellimm.2004.04.001

292. Piccio L, Stark JL, Cross AH. Chronic Calorie Restriction Attenuates Experimental Autoimmune Encephalomyelitis. J Leukoc Biol (2008) 84 (4):940-8. doi: 10.1189/jlb.0208133

293. Kafami L, Raza M, Razavi A, Mirshafiey A, Movahedian M, Khorramizadeh MR. Intermittent Feeding Attenuates Clinical Course of Experimental Autoimmune Encephalomyelitis in C57BL/6 Mice. Avicenna J Med Biotechnol (2010) 2(1):47.

294. Bai M, Wang Y, Han R, Xu L, Huang M, Zhao J, et al. Intermittent Caloric Restriction With a Modified Fasting-Mimicking Diet Ameliorates Autoimmunity and Promotes Recovery in a Mouse Model of Multiple Sclerosis. J Nutr Biochem (2021) 87:108493. doi: 10.1016/j.jnutbio.2020.108493

295. Mojaverrostami S, Pasbakhsh P, Madadi S, Nekoonam S, Zarini D, Noori L, et al. Calorie Restriction Promotes Remyelination in a Cuprizone-Induced Demyelination Mouse Model of Multiple Sclerosis. Metab Brain Dis (2020) 35(7):1211-24. doi: 10.1007/s11011-020-00597-0

296. Chandrasekar B, McGuff HS, Aufdermorte TB, Troyer DA, Talal N, Fernandes G. Effects of Calorie Restriction on Transforming Growth Factor $\beta 1$ and Proinflammatory Cytokines in Murine Sjogren's Syndrome. Clin Immunol Immunopathol (1995) 76(3):291-6. doi: 10.1006/ clin.1995.1128

297. O'Neill LA, Kishton RJ, Rathmell J. A Guide to Immunometabolism for Immunologists. Nat Rev Immunol (2016) 16(9):553. doi: 10.1038/nri.2016.70

298. Loftus RM, Finlay DK. Immunometabolism: Cellular Metabolism Turns Immune Regulator. J Biol Chem (2016) 291(1):1-10. doi: 10.1074/ jbc.R115.693903

299. Buck MD, O'sullivan D, Pearce EL. T Cell Metabolism Drives Immunity. J Exp Med (2015) 212(9):1345-60. doi: 10.1084/jem.20151159

300. Saha S, Shalova IN, Biswas SK. Metabolic Regulation of Macrophage Phenotype and Function. Immunol Rev (2017) 280(1):102-11. doi: $10.1111 / \mathrm{imr} .12603$
301. Boothby M, Rickert RC. Metabolic Regulation of the Immune Humoral Response. Immunity (2017) 46(5):743-55. doi: 10.1016/j.immuni. 2017.04.009

302. MacIver NJ, Michalek RD, Rathmell JC. Metabolic Regulation of T Lymphocytes. Annu Rev Immunol (2013) 31:259-83. doi: 10.1146/ annurev-immunol-032712-095956

303. Wahl D, Petersen B, Warner R, Richardson B, Glick G, Opipari A. Characterization of the Metabolic Phenotype of Chronically Activated Lymphocytes. Lupus (2010) 19(13):1492-501. doi: 10.1177/ 0961203310373109

304. Winer S, Paltser G, Chan Y, Tsui H, Engleman E, Winer D, et al. Obesity Predisposes to Th17 Bias. Eur J Immunol (2009) 39(9):2629-35. doi: 10.1002/ eji.200838893

305. Kane LP, Weiss A. The PI-3 Kinase/Akt Pathway and T Cell Activation: Pleiotropic Pathways Downstream of PIP3. Immunol Rev (2003) 192(1):720. doi: 10.1034/j.1600-065X.2003.00008.x

306. Handi J, Patterson SJ, Levings M. The Role of the PI3K Signaling Pathway in CD4+ T Cell Differentiation and Function. Front Immunol (2012) 3:245. doi: 10.3389/fimmu.2012.00245

307. Garçon F, Patton DT, Emery JL, Hirsch E, Rottapel R, Sasaki T, et al. CD28 Provides T-Cell Costimulation and Enhances PI3K Activity at the Immune Synapse Independently of Its Capacity to Interact With the P85/P110 Heterodimer. Blood (2008) 111(3):1464-71. doi: 10.1182/blood-2007-08108050

308. Huang J, Manning BD. A Complex Interplay Between Akt, TSC2 and the Two mTOR Complexes. Biochem Soc Trans (2009) 37(1):217-22. doi: 10.1042/BST0370217

309. Powell JD, Delgoffe GM. The Mammalian Target of Rapamycin: Linking T Cell Differentiation, Function, and Metabolism. Immunity (2010) 33(3):30111. doi: 10.1016/j.immuni.2010.09.002

310. Bi Y, Liu G, Yang R. mTOR Regulates T-Cell Differentiation and Activation in Immunity and Autoimmunity. Crit Rev Eukaryot Gene Expr (2011) 21 (4):313-22. doi: 10.1615/CritRevEukarGeneExpr.v21.i4.20

311. Keating R, McGargill MA. mTOR Regulation of Lymphoid Cells in Immunity to Pathogens. Front Immunol (2016) 7:180. doi: 10.3389/ fimmu.2016.00180

312. Perl A. Activation of mTOR (Mechanistic Target of Rapamycin) in Rheumatic Diseases. Nat Rev Rheumatol (2016) 12(3):169-82. doi: 10.1038/nrrheum.2015.172

313. Kato H, Perl A. Mechanistic Target of Rapamycin Complex 1 Expands Th17 and IL-4+ CD4- CD8- Double-Negative T Cells and Contracts Regulatory T Cells in Systemic Lupus Erythematosus. J Immunol (2014) 192(9):4134-44. doi: 10.4049/jimmunol.1301859

314. Wu C, Fu Q, Guo Q, Chen S, Goswami S, Sun S, et al. Lupus-Associated Atypical Memory B Cells Are Mtorc1-Hyperactivated and Functionally Dysregulated. Ann Rheum Dis (2019) 78(8):1090-100. doi: 10.1136/ annrheumdis-2019-215039

315. Tuijnenburg P, van de Kerk DJ, Jansen MH, Morris B, Lieftink C, Beijersbergen RL, et al. High-Throughput Compound Screen Reveals mTOR Inhibitors as Potential Therapeutics to Reduce (Auto) Antibody Production by Human Plasma Cells. Eur J Immunol (2020) 50(1):73-85. doi: 10.1002/eji.201948241

316. Raybuck AL, Cho SH, Li J, Rogers MC, Lee K, Williams CL, et al. B CellIntrinsic Mtorc1 Promotes Germinal Center-Defining Transcription Factor Gene Expression, Somatic Hypermutation, and Memory B Cell Generation in Humoral Immunity. J Immunol (2018) 200(8):2627-39. doi: 10.4049/ jimmunol.1701321

317. Snyder JP, Amiel E. Regulation of Dendritic Cell Immune Function and Metabolism by Cellular Nutrient Sensor Mammalian Target of Rapamycin (mTOR). Front Immunol (2019) 9:3145. doi: 10.3389/fimmu.2018.03145

318. Katholnig K, Linke M, Pham H, Hengstschläger M, Weichhart T. Immune Responses of Macrophages and Dendritic Cells Regulated by mTOR Signalling. Biochem Soc Trans (2013) 41(4):927-33. doi: 10.1042/ BST20130032

319. Gergely P, Grossman C, Niland B, Puskas F, Neupane H, Allam F, et al. Mitochondrial Hyperpolarization and ATP Depletion in Patients With Systemic Lupus Erythematosus. Arthritis Rheum (2002) 46(1):175-90. doi: 10.1002/1529-0131(200201)46:1<175::AID-ART10015>3.0.CO;2-H 
320. Tsokos GC. Cellular and Metabolic Requirements of Effector T Cells. Nat Rev Rheumatol (2016) 12(2):74-6. doi: 10.1038/nrrheum.2015.178

321. Howell JJ, Manning BD. mTOR Couples Cellular Nutrient Sensing to Organismal Metabolic Homeostasis. Trends Endocrinol Metab (2011) 22 (3):94-102. doi: 10.1016/j.tem.2010.12.003

322. Jewell JL, Guan K-L. Nutrient Signaling to mTOR and Cell Growth. Trends Biochem Sci (2013) 38(5):233-42. doi: 10.1016/j.tibs.2013.01.004

323. Procaccini C, De Rosa V, Galgani M, Carbone F, Cassano S, Greco D, et al. Leptin-Induced mTOR Activation Defines a Specific Molecular and Transcriptional Signature Controlling CD4+ Effector T Cell Responses. J Immunol (2012) 189(6):2941-53. doi: 10.4049/jimmunol.1200935

324. O'Sullivan D, Pearce EL. Targeting T Cell Metabolism for Therapy. Trends Immunol (2015) 36(2):71-80. doi: 10.1016/j.it.2014.12.004

325. Fan X-X, Pan H-D, Li Y, Guo R-J, Leung EL-H, Liu L. Novel Therapeutic Strategy for Cancer and Autoimmune Conditions: Modulating Cell Metabolism and Redox Capacity. Pharmacol Ther (2018) 191:148-61. doi: 10.1016/j.pharmthera.2018.06.010

326. Christadoss P, Talal N, Lindstrom J, Fernandes G. Suppression of Cellular and Humoral Immunity to T-Dependent Antigens by Calorie Restriction. Cell Immunol (1984) 88(1):1-8. doi: 10.1016/0008-8749(84)90046-7

327. Jordan S, Tung N, Casanova-Acebes M, Chang C, Cantoni C, Zhang D, et al. Dietary Intake Regulates the Circulating Inflammatory Monocyte Pool. Cell (2019) 178(5):1102-14.e17. doi: 10.1016/j.cell.2019.07.050

328. Fernandes G, Good RA. Inhibition by Restricted-Calorie Diet of Lymphoproliferative Disease and Renal Damage in MRL/lpr Mice. Proc Natl Acad Sci (1984) 81(19):6144-8. doi: 10.1073/pnas.81.19.6144

329. Luan X, Zhao W, Chandrasekar B, Fernandes G. Calorie Restriction Modulates Lymphocyte Subset Phenotype and Increases Apoptosis in MRLlpr Mice. Immunol Lett (1995) 47(3):181-6. doi: 10.1016/0165-2478 (95)00091-5

330. S Shushimita, P van der Pol, RW de Bruin, JN IJzermans, C van Kooten and FJ Dor eds. Dietary Restriction and Fasting Downregulate Complement Activity. BMC Proc (2012) 6:P66. doi: 10.1186/1753-6561-6-S3-P66

331. Bourke CD, Berkley JA, Prendergast AJ. Immune Dysfunction as a Cause and Consequence of Malnutrition. Trends Immunol (2016) 37(6):386-98. doi: 10.1016/j.it.2016.04.003

332. Kurtz A, Grant K, Marano R, Arrieta A, Feaster W, Steele C, et al. Long-Term Effects of Malnutrition on Severity of COVID-19. Sci Rep (2021) 11(1):1-8. doi: 10.1038/s41598-021-94138-z

333. Mertens E, Peñalvo JL. The Burden of Malnutrition and Fatal COVID-19: A Global Burden of Disease Analysis. Front Nutr (2021) 7:351. doi: 10.3389/ fnut.2020.619850

334. Brugliera L, Spina A, Castellazzi P, Cimino P, Arcuri P, Negro A, et al. Nutritional Management of COVID-19 Patients in a Rehabilitation Unit. Eur J Clin Nutr (2020) 74(6):860-3. doi: 10.1038/s41430-020-0664-x

335. Maeshima E, Liang X-M, Goda M, Otani H, Mune M. The Efficacy of Vitamin E Against Oxidative Damage and Autoantibody Production in Systemic Lupus Erythematosus: A Preliminary Study. Clin Rheumatol (2007) 26(3):401-4. doi: 10.1007/s10067-006-0477-x

336. Reynolds JA, Rosenberg AZ, Smith CK, Sergeant JC, Rice GI, Briggs TA, et al. Brief Report: Vitamin D Deficiency Is Associated With Endothelial Dysfunction and Increases Type I Interferon Gene Expression in a Murine Model of Systemic Lupus Erythematosus. Arthritis Rheumatol (2016) 68 (12):2929-35. doi: 10.1002/art.39803

337. Huang J, An Q, Ju B-m, Zhang J, Fan P, He L, et al. Role of Vitamin D/VDR Nuclear Translocation in Down-Regulation of NF-kb/NLRP3/caspase-1 Axis in Lupus Nephritis. Int Immunopharmacol (2021) 100:108131. doi: 10.1016/j.intimp.2021.108131

338. Attar SM, Siddiqui AM. Vitamin D Deficiency in Patients With Systemic Lupus Erythematosus. Oman Med J (2013) 28(1):42. doi: 10.5001/omj. 2013.10

339. Bogaczewicz J, Sysa-Jedrzejowska A, Arkuszewska C, Zabek J, Kontny E, McCauliffe D, et al. Vitamin D Status in Systemic Lupus Erythematosus Patients and Its Association With Selected Clinical and Laboratory Parameters. Lupus (2012) 21(5):477-84. doi: 10.1177/0961203311427549

340. Charoenwoodhipong P, Harlow SD, Marder W, Hassett AL, McCune WJ, Gordon C, et al. Dietary Omega Polyunsaturated Fatty Acid Intake and Patient-Reported Outcomes in Systemic Lupus Erythematosus: The
Michigan Lupus Epidemiology and Surveillance Program. Arthritis Care Res (2020) 72(7):874-81. doi: 10.1002/acr.23925

341. Georgountzou A, Papadopoulos NG. Postnatal Innate Immune Development: From Birth to Adulthood. Front Immunol (2017) 8:957. doi: 10.3389/fimmu.2017.00957

342. Adkins B, Leclerc C, Marshall-Clarke S. Neonatal Adaptive Immunity Comes of Age. Nat Rev Immunol (2004) 4(7):553-64. doi: 10.1038/nri1394

343. Muthukkumar S, Goldstein J, Stein KE. The Ability of B Cells and Dendritic Cells to Present Antigen Increases During Ontogeny. J Immunol (2000) 165 (9):4803-13. doi: 10.4049/jimmunol.165.9.4803

344. Filias A, Theodorou GL, Mouzopoulou S, Varvarigou AA, Mantagos S, Karakantza M. Phagocytic Ability of Neutrophils and Monocytes in Neonates. BMC Pediatr (2011) 11(1):1-6. doi: 10.1186/1471-2431-11-29

345. Wang G, Miyahara Y, Guo Z, Khattar M, Stepkowski SM, Chen W. "Default" Generation of Neonatal Regulatory T Cells. J Immunol (2010) 185(1):71-8. doi: 10.4049/jimmunol.0903806

346. Debock I, Flamand V. Unbalanced Neonatal CD4+ T-Cell Immunity. Front Immunol (2014) 5:393. doi: 10.3389/fimmu.2014.00393

347. Wilson C, Westall J, Johnston L, Lewis D, Dower S, Alpert A. Decreased Production of Interferon-Gamma by Human Neonatal Cells. Intrinsic and Regulatory Deficiencies. J Clin Invest (1986) 77(3):860-7. doi: 10.1111/ j.1365-2249.1995.tb06655.x

348. Schenten D, Medzhitov R. The Control of Adaptive Immune Responses by the Innate Immune System. Adv Immunol (2011) 109:87-124. doi: 10.1016/ B978-0-12-387664-5.00003-0

349. Gollwitzer ES, Marsland BJ. Impact of Early-Life Exposures on Immune Maturation and Susceptibility to Disease. Trends Immunol (2015) 36 (11):684-96. doi: 10.1016/j.it.2015.09.009

350. Chung H, Pamp SJ, Hill JA, Surana NK, Edelman SM, Troy EB, et al. Gut Immune Maturation Depends on Colonization With a Host-Specific Microbiota. Cell (2012) 149(7):1578-93. doi: 10.1016/j.cell.2012.04.037

351. Arrieta M-C, Finlay BB. The Commensal Microbiota Drives Immune Homeostasis. Front Immunol (2012) 3:33. doi: 10.3389/fimmu.2012. 00033

352. Byndloss MX, Olsan EE, Rivera-Chávez F, Tiffany CR, Cevallos SA, Lokken $\mathrm{KL}$, et al. Microbiota-Activated PPAR- $\gamma$ Signaling Inhibits Dysbiotic Enterobacteriaceae Expansion. Science (2017) 357(6351):570-5. doi: 10.1126/science.aam9949

353. Wang B, Yao M, Lv L, Ling Z, Li L. The Human Microbiota in Health and Disease. Engineering (2017) 3(1):71-82. doi: 10.1016/J.ENG.2017.01.008

354. Gollwitzer ES, Saglani S, Trompette A, Yadava K, Sherburn R, McCoy KD, et al. Lung Microbiota Promotes Tolerance to Allergens in Neonates via PDL1. Nat Med (2014) 20(6):642-7. doi: 10.1038/nm.3568

355. Herbst T, Sichelstiel A, Schär C, Yadava K, Bürki K, Cahenzli J, et al. Dysregulation of Allergic Airway Inflammation in the Absence of Microbial Colonization. Am J Respir Crit Care Med (2011) 184(2):198-205. doi: 10.1164/rccm.201010-1574OC

356. Tanaka S, Kobayashi T, Songjinda P, Tateyama A, Tsubouchi M, Kiyohara C, et al. Influence of Antibiotic Exposure in the Early Postnatal Period on the Development of Intestinal Microbiota. FEMS Immunol Med Microbiol (2009) 56(1):80-7. doi: 10.1111/j.1574-695X.2009.00553.x

357. Loss G, Bitter S, Wohlgensinger J, Frei R, Roduit C, Genuneit J, et al. Prenatal and Early-Life Exposures Alter Expression of Innate Immunity Genes: The PASTURE Cohort Study. J Allergy Clin Immunol (2012) 130(2):523-30. e9. doi: 10.1016/j.jaci.2012.05.049

358. Cahenzli J, Köller Y, Wyss M, Geuking MB, McCoy KD. Intestinal Microbial Diversity During Early-Life Colonization Shapes Long-Term IgE Levels. Cell Host Microbe (2013) 14(5):559-70. doi: 10.1016/j.chom.2013.10.004

359. Zeissig S, Blumberg RS. Life at the Beginning: Perturbation of the Microbiota by Antibiotics in Early Life and Its Role in Health and Disease. Nat Immunol (2014) 15(4):307-10. doi: 10.1038/ni.2847

360. Zhou Y, Han T, Chen J, Hou C, Hua L, He S, et al. Clinical and Autoimmune Characteristics of Severe and Critical Cases of COVID-19. Clin Trans Sci (2020) 13(6):1077-86. doi: 10.1111/cts.12805

361. Licciardi F, Pruccoli G, Denina M, Parodi E, Taglietto M, Rosati S, et al. SARS-CoV-2-Induced Kawasaki-Like Hyperinflammatory Syndrome: A Novel COVID Phenotype in Children. Pediatrics (2021) 97(2):140-59. doi: $10.1542 /$ peds.2020-1711 
362. Zhang Y, Xiao M, Zhang S, Xia P, Cao W, Jiang W, et al. Coagulopathy and Antiphospholipid Antibodies in Patients With Covid-19. N Engl J Med (2020) 382(17):e38. doi: 10.1056/NEJMc2007575

363. Cardoso EM, Hundal J, Feterman D, Magaldi J. Concomitant New Diagnosis of Systemic Lupus Erythematosus and COVID-19 With Possible Antiphospholipid Syndrome. Just a Coincidence? A Case Report and Review of Intertwining Pathophysiology. Clin Rheumatol (2020) 39 (9):2811-5. doi: 10.1007/s10067-020-05310-1

364. Lazarian G, Quinquenel A, Bellal M, Siavellis J, Jacquy C, Re D, et al. Autoimmune Haemolytic Anaemia Associated With COVID-19 Infection. Br J Haematol (2020), 29-31. doi: 10.1111/bjh.16794

365. Zanin L, Saraceno G, Panciani PP, Renisi G, Signorini L, Migliorati K, et al. SARS-CoV-2 Can Induce Brain and Spine Demyelinating Lesions. Acta Neurochir (2020) 162(7):1491-4. doi: 10.1007/s00701-020-04374-x

366. Galeotti C, Bayry J. Autoimmune and Inflammatory Diseases Following COVID-19. Nat Rev Rheumatol (2020) 16(8):413-4. doi: 10.1038/s41584020-0448-7

367. Wucherpfennig KW. Mechanisms for the Induction of Autoimmunity by Infectious Agents. J Clin Invest (2001) 108(8):1097-104. doi: 10.1172/ JCI200114235

368. Bach J-F. Infections and Autoimmune Diseases. J Autoimmun (2005) 25:7480. doi: 10.1016/j.jaut.2005.09.024

369. Nawata NS, Yamada M, Sekigawa I, Iida N, Hashimoto H. Possible Triggering Effect of Cytomegalovirus Infection on Systemic Lupus Erythematosus. Scand J Rheumatol (2001) 30(6):360-2. doi: 10.1080/ 030097401317148570

370. Hayashi T, Lee S, Ogasawara H, Sekigawa I, Iida N, Tomino Y, et al. Exacerbation of Systemic Lupus Erythematosus Related to Cytomegalovirus Infection. Lupus (1998) 7(8):561-4. doi: 10.1191/096120398678920596

371. James JA, Kaufman KM, Farris AD, Taylor-Albert E, Lehman T, Harley JB. An Increased Prevalence of Epstein-Barr Virus Infection in Young Patients Suggests a Possible Etiology for Systemic Lupus Erythematosus. J Clin Invest (1997) 100(12):3019-26. doi: 10.1172/JCI119856

372. Sundar K, Jacques S, Gottlieb P, Villars R, Benito M-E, Taylor DK, et al. Expression of the Epstein-Barr Virus Nuclear Antigen-1 (EBNA-1) in the Mouse Can Elicit the Production of anti-dsDNA and Anti-Sm Antibodies. J Autoimmun (2004) 23(2):127-40. doi: 10.1016/j.jaut.2004.06.001

373. Pan Q, Liu Z, Liao S, Ye L, Lu X, Chen X, et al. Current Mechanistic Insights Into the Role of Infection in Systemic Lupus Erythematosus. Biomed Pharmacother (2019) 117:109122. doi: 10.1016/j.biopha.2019.109122

374. Lin S-h, Zhao Y-s, Zhou D-x, Zhou F-c, Xu F. Coronavirus Disease 2019 (COVID-19): Cytokine Storms, Hyper-Inflammatory Phenotypes, and Acute Respiratory Distress Syndrome. Genes Dis (2020) (4):520-7. doi: 10.1016/ j.gendis.2020.06.009

375. Lin Y, Lin C, Fang Y, Kuo Y, Liao P-C, Yeh T, et al. Antibody to Severe Acute Respiratory Syndrome (SARS)-Associated Coronavirus Spike Protein Domain 2 Cross-Reacts With Lung Epithelial Cells and Causes Cytotoxicity. Clin Exp Immunol (2005) 141(3):500-8. doi: 10.1111/j.13652249.2005.02864.x

376. Gupta M, Weaver DF. COVID-19 as a Trigger of Brain Autoimmunity. ACS Chem Neurosci (2021) 12(14):2558-61. doi: 10.1021/acschemneuro.1c00403

377. Greenwood B, Herrick EM, Voller A. Suppression of Autoimmune Disease in NZB and $(\mathrm{NZB} \times \mathrm{NZW}) \mathrm{F} 1$ Hybrid Mice by Infection With Malaria. Nature (1970) 226(5242):266-7. doi: 10.1038/226266a0

378. Sewell DL, Reinke EK, Hogan LH, Sandor M, Fabry Z. Immunoregulation of CNS Autoimmunity by Helminth and Mycobacterial Infections. Immunol Lett (2002) 82(1-2):101-10. doi: 10.1016/S0165-2478(02)00025-1

379. Oldstone M. Prevention of Type I Diabetes in Nonobese Diabetic Mice by Virus Infection. Science (1988) 239(4839):500-2. doi: 10.1126/ science. 3277269

380. Pross HF, Eidinger D. Antigenic Competition: A Review of Nonspecific Antigen-Induced Suppression. Adv Immunol (1974) 18:133-68. doi: 10.1016/S0065-2776(08)60309-0

381. Xiong Y, Murphy M, Manavalan TT, Pattabiraman G, Qiu F, Chang H-H, et al. Endotoxin Tolerance Inhibits Lyn and C-Src Phosphorylation and Association With Toll-Like Receptor 4 But Increases Expression and Activity of Protein Phosphatases. J Innate Immun (2016) 8(2):171-84. doi: 10.1159/ 000440838
382. Medvedev AE, Kopydlowski KM, Vogel SN. Inhibition of Lipopolysaccharide-Induced Signal Transduction in Endotoxin-Tolerized Mouse Macrophages: Dysregulation of Cytokine, Chemokine, and Toll-Like Receptor 2 and 4 Gene Expression. J Immunol (2000) 164(11):5564-74. doi: 10.4049/jimmunol.164.11.5564

383. Kim D-H, Lee J-C, Kim S, Oh SH, Lee M-K, Kim K-W, et al. Inhibition of Autoimmune Diabetes by TLR2 Tolerance. J Immunol (2011) 187(10):521120. doi: 10.4049/jimmunol.1001388

384. Anstadt EJ, Fujiwara M, Wasko N, Nichols F, Clark RB. TLR Tolerance as a Treatment for Central Nervous System Autoimmunity. J Immunol (2016) 197(6):2110-8. doi: 10.4049/jimmunol.1600876

385. Henry T, Kirimanjeswara GS, Ruby T, Jones JW, Peng K, Perret M, et al. Type I IFN Signaling Constrains IL-17a/F Secretion by $\gamma \delta$ T Cells During Bacterial Infections. J Immunol (2010) 184(7):3755-67. doi: 10.4049/ jimmunol.0902065

386. Miller FW. Environmental Agents and Autoimmune Diseases. In: Epigenetic Contributions in Autoimmune Disease (2011) 711:61-81.

387. Faa G, Gerosa C, Fanni D, Nemolato S, van Eyken P, Fanos V. Factors Influencing the Development of a Personal Tailored Microbiota in the Neonate, With Particular Emphasis on Antibiotic Therapy. J Matern Fetal Neonatal Med (2013) 26(sup2):35-43. doi: 10.3109/14767058.2013.829700

388. Engelbrektson A, Korzenik JR, Pittler A, Sanders ME, Klaenhammer TR, Leyer G, et al. Probiotics to Minimize the Disruption of Faecal Microbiota in Healthy Subjects Undergoing Antibiotic Therapy. J Med Microbiol (2009) 58 (5):663-70. doi: 10.1099/jmm.0.47615-0

389. Lankelma JM, Cranendonk DR, Belzer C, De Vos AF, De Vos WM, van der Poll T, et al. Antibiotic-Induced Gut Microbiota Disruption During Human Endotoxemia: A Randomised Controlled Study. Gut (2017) 66(9):1623-30. doi: 10.1136/gutinl-2016-312132

390. Nagao-Kitamoto H, Shreiner AB, Gillilland MGIII, Kitamoto S, Ishii C, Hirayama A, et al. Functional Characterization of Inflammatory Bowel Disease-Associated Gut Dysbiosis in Gnotobiotic Mice. Cell Mol Gastroenterol Hepatol (2016) 2(4):468-81. doi: 10.1016/j.jcmgh.2016.02.003

391. Scher JU, Ubeda C, Artacho A, Attur M, Isaac S, Reddy SM, et al. Decreased Bacterial Diversity Characterizes the Altered Gut Microbiota in Patients With Psoriatic Arthritis, Resembling Dysbiosis in Inflammatory Bowel Disease. Arthritis Rheumatol (2015) 67(1):128-39. doi: 10.1002/art.38892

392. Nishino K, Nishida A, Inoue R, Kawada Y, Ohno M, Sakai S, et al. Analysis of Endoscopic Brush Samples Identified Mucosa-Associated Dysbiosis in Inflammatory Bowel Disease. J Gastroenterol (2018) 53(1):95-106. doi: 10.1007/s00535-017-1384-4

393. He Z, Shao T, Li H, Xie Z, Wen C. Alterations of the Gut Microbiome in Chinese Patients With Systemic Lupus Erythematosus. Gut Pathog (2016) 8 (1):1-7. doi: 10.1186/s13099-016-0146-9

394. Luo XM, Edwards MR, Mu Q, Yu Y, Vieson MD, Reilly CM, et al. Gut Microbiota in Human Systemic Lupus Erythematosus and a Mouse Model of Lupus. Appl Environ Microbiol (2018) 84(4):e02288-17. doi: 10.1128/ AEM.02288-17

395. Neuman H, Koren O. The Gut Microbiota: A Possible Factor Influencing Systemic Lupus Erythematosus. Curr Opin Rheumatol (2017) 29(4):374-7. doi: 10.1097/BOR.0000000000000395

396. Guo M, Wang H, Xu S, Zhuang Y, An J, Su C, et al. Alteration in Gut Microbiota Is Associated With Dysregulation of Cytokines and Glucocorticoid Therapy in Systemic Lupus Erythematosus. Gut Microbes (2020) 11(6):1758-73. doi: 10.1080/19490976.2020.1768644

397. Li B-Z, Zhou H-Y, Guo B, Chen W-J, Tao J-H, Cao N-W, et al. Dysbiosis of Oral Microbiota Is Associated With Systemic Lupus Erythematosus. Arch Oral Biol (2020) 113:104708. doi: 10.1016/j.archoralbio.2020.104708

398. Moore LD, Robbins G, Quinn J, Arbogast JW. The Impact of COVID-19 Pandemic on Hand Hygiene Performance in Hospitals. Am J Infect Control (2021) 49(1):30-3. doi: 10.1016/j.ajic.2020.08.021

399. Dwipayanti NMU, Lubis DS, Harjana NPA. Public Perception and Hand Hygiene Behavior During COVID-19 Pandemic in Indonesia. Front Public Health (2021) 9:543. doi: 10.3389/fpubh.2021.621800

400. Choi K, Sim S, Choi J, Park C, Uhm Y, Lim E, et al. Changes in Handwashing and Hygiene Product Usage Patterns in Korea Before and After the Outbreak of COVID-19. Environ Sci Eur (2021) 33(1):1-10. doi: 10.1186/s12302-02100517-8 
401. Finlay BB, Amato KR, Azad M, Blaser MJ, Bosch TC, Chu H, et al. The Hygiene Hypothesis, the COVID Pandemic, and Consequences for the Human Microbiome. Proc Natl Acad Sci (2021) 118(6):e2010217118. doi: 10.1073/pnas.2010217118

402. Ejtahed H-S, Hasani-Ranjbar S, Siadat SD, Larijani B. The Most Important Challenges Ahead of Microbiome Pattern in the Post Era of the COVID-19 Pandemic. J Diabetes Metab Disord (2020) 19(2):2031-3. doi: 10.1007/ s40200-020-00579-0

403. Yeoh YK, Zuo T, Lui GC-Y, Zhang F, Liu Q, Li AY, et al. Gut Microbiota Composition Reflects Disease Severity and Dysfunctional Immune Responses in Patients With COVID-19. Gut (2021) 70(4):698-706. doi: 10.1136/gutjnl-2020-323020

404. Zhang Y, Zhao F, Deng Y, Zhao Y, Ren H. Metagenomic and Metabolomic Analysis of the Toxic Effects of Trichloroacetamide-Induced Gut Microbiome and Urine Metabolome Perturbations in Mice. J Proteome Res (2015) 14(4):1752-61. doi: 10.1021/pr5011263

405. Murri M, Leiva I, Gomez-Zumaquero JM, Tinahones FJ, Cardona F, Soriguer F, et al. Gut Microbiota in Children With Type 1 Diabetes Differs From That in Healthy Children: A Case-Control Study. BMC Med (2013) 11(1):1-12. doi: 10.1186/1741-7015-11-46

406. Man SM, Kaakoush NO, Mitchell HM. The Role of Bacteria and PatternRecognition Receptors in Crohn's Disease. Nat Rev Gastroenterol Hepatol (2011) 8(3):152. doi: 10.1038/nrgastro.2011.3

407. Hevia A, Milani C, López P, Cuervo A, Arboleya S, Duranti S, et al. Intestinal Dysbiosis Associated With Systemic Lupus Erythematosus. MBio (2014) 5 (5):e01548-14. doi: 10.1128/mBio.01548-14

408. Gao B, Tu P, Bian X, Chi L, Ru H, Lu K. Profound Perturbation Induced by Triclosan Exposure in Mouse Gut Microbiome: A Less Resilient Microbial Community With Elevated Antibiotic and Metal Resistomes. BMC Pharmacol Toxicol (2017) 18(1):1-12. doi: 10.1186/s40360-017-0150-9

409. Wang C, Yu Z, Shi X, Tang X, Wang Y, Wang X, et al. Triclosan Enhances the Clearing of Pathogenic Intracellular Salmonella or Candida Albicans But Disturbs the Intestinal Microbiota Through mTOR-Independent Autophagy. Front Cell Infect Microbiol (2018) 8:49. doi: 10.3389/fcimb.2018.00049

410. Narrowe AB, Albuthi-Lantz M, Smith EP, Bower KJ, Roane TM, Vajda AM, et al. Perturbation and Restoration of the Fathead Minnow Gut Microbiome After Low-Level Triclosan Exposure. Microbiome (2015) 3(1):1-18. doi: 10.1186/s40168-015-0069-6

411. Bever CS, Rand AA, Nording M, Taft D, Kalanetra KM, Mills DA, et al. Effects of Triclosan in Breast Milk on the Infant Fecal Microbiome. Chemosphere (2018) 203:467-73. doi: 10.1016/j.chemosphere.2018.03.186

412. Tun MH, Tun HM, Mahoney JJ, Konya TB, Guttman DS, Becker AB, et al. Postnatal Exposure to Household Disinfectants, Infant Gut Microbiota and Subsequent Risk of Overweight in Children. CMAJ (2018) 190(37):E1097E107. doi: 10.1503/cmaj.170809
413. Zhang H, Liao X, Sparks JB, Luo XM. Dynamics of Gut Microbiota in Autoimmune Lupus. Appl Environ Microbiol (2014) 80(24):7551-60. doi: 10.1128/AEM.02676-14

414. McDonnell G, Russell AD. Antiseptics and Disinfectants: Activity, Action, and Resistance. Clin Microbiol Rev (1999) 12(1):147-79. doi: 10.1128/ CMR.12.1.147

415. McDonald VA. Evaluating Immunotoxicity of Quaternary Ammonium Compounds. Virginia Tech Electronic Theses and Dissertations (ETDs) (2017). Available at: http://hdl.handle.net/10919/79723.

416. Muñoz LE, Lauber K, Schiller M, Manfredi AA, Herrmann M. The Role of Defective Clearance of Apoptotic Cells in Systemic Autoimmunity. Nat Rev Rheumatol (2010) 6(5):280. doi: 10.1038/nrrheum.2010.46

417. Abdolmaleki F, Farahani N, Gheibi Hayat SM, Pirro M, Bianconi V, Barreto GE, et al. The Role of Efferocytosis in Autoimmune Diseases. Front Immunol (2018) 9:1645. doi: 10.3389/fimmu.2018.01645

418. Abdelhamid L, Cabana-Puig X, Mu Q, Moarefian M, Swartwout B, Eden K, et al. Quaternary Ammonium Compound Disinfectants Reduce LupusAssociated Splenomegaly by Targeting Neutrophil Migration and T-Cell Fate. Front Immunol (2020) 11. doi: 10.3389/fimmu.2020.575179

419. Salas LA, Bustamante M, Gonzalez JR, Gracia-Lavedan E, Moreno V, Kogevinas M, et al. DNA Methylation Levels and Long-Term Trihalomethane Exposure in Drinking Water: An Epigenome-Wide Association Study. Epigenetics (2015) 10(7):650-61. doi: 10.1080/ 15592294.2015 .1057672

420. Wilson CB, Rowell E, Sekimata M. Epigenetic Control of T-Helper-Cell Differentiation. Nat Rev Immunol (2009) 9(2):91-105. doi: 10.1038/nri2487

421. Richardson B. DNA Methylation and Autoimmune Disease. Clin Immunol (2003) 109(1):72-9. doi: 10.1016/S1521-6616(03)00206-7

Conflict of Interest: The authors declare that the research was conducted in the absence of any commercial or financial relationships that could be construed as a potential conflict of interest.

Publisher's Note: All claims expressed in this article are solely those of the authors and do not necessarily represent those of their affiliated organizations, or those of the publisher, the editors and the reviewers. Any product that may be evaluated in this article, or claim that may be made by its manufacturer, is not guaranteed or endorsed by the publisher.

Copyright () 2022 Abdelhamid and Luo. This is an open-access article distributed under the terms of the Creative Commons Attribution License (CC BY). The use, distribution or reproduction in other forums is permitted, provided the original author(s) and the copyright owner(s) are credited and that the original publication in this journal is cited, in accordance with accepted academic practice. No use, distribution or reproduction is permitted which does not comply with these terms. 